\title{
Effect of bis(triethoxysilylpropyl) tetrasulfide (TESPT) on properties of carbon nanotubes and conductive carbon black hybrid filler filled natural rubber nanocomposites
}

\author{
Y. Nakaramontri $^{1 *}$, C. Kummerlöwe ${ }^{2}$, N. Vennemann $^{2}$, S. Wisunthorn ${ }^{1}$, S. Pichaiyut ${ }^{1}$, C. Nakason ${ }^{1}$ \\ ${ }^{1}$ Faculty of Science and Industrial Technology, Prince of Songkla University, 84000 Surat Thani Campus, Thailand \\ ${ }^{2}$ Faculty of Engineering and Computer Science, University of Applied Sciences Osnabrück, 49076 Osnabrück, Germany
}

Received 2 March 2018; accepted in revised form 8 May 2018

\begin{abstract}
Natural rubber (NR) and epoxidized natural rubber (ENR) vulcanizates reinforced by carbon nanotubes (CNT), conductive carbon black (CCB) and CNT/CCB hybrid filler without and with bis(triethoxysilylpropyl)tetrasulfide (TESPT) silane coupling agent were prepared using an internal mixer and a two-roll mill. Attenuated total reflection infrared spectroscopy (ATR-FTIR) was used to determine chemical interactions among rubber molecules, filler surfaces and silane molecules. In addition, the filler-filler interaction in NR and ENR matrices were assessed from wetting ability and Payne effect. Furthermore, the coupling by TESPT of filler surfaces and rubber molecules was clarified by temperature stress scanning relaxation (TSSR) technique. It was found that the rubber bound by physical absorption decreased with addition of TESPT, while the chemically bound amount significantly increased. This correlates well with estimates of physically and chemically bound rubber from swelling method and morphological properties. It was also found that the optimal electrical conductivity, percolation threshold concentration and dielectric constant of the composites were effectively improved by addition of TESPT. The improvement was confirmed by ANOVA. This indicates a great opportunity to manufacture smart materials with superior conductivity and dielectric constant, together with optimal scorch time, cure time and crosslinking properties.
\end{abstract}

Keywords: polymer composites, natural rubber, carbon nanotube, conductive carbon black, silane coupling agent

\section{Introduction}

Electrically conductive natural rubber (NR) composites reinforced by carbon nanotubes (CNT) have been developed for a decade. So far the optimal conductivity $\left(\Theta_{\max }\right)$ of the NR/CNT composites has remained at about $10^{-2} \mu \mathrm{S} / \mathrm{cm}$ with low percolation threshold concentration $\left(\varphi_{\mathrm{c}}\right)$ of approximately $3 \mathrm{phr}$ of CNT [1]. On the other hand, the $\Theta_{\max }$ and $\varphi_{c}$ of the composites were significantly improved, reaching $10 \mu \mathrm{S} / \mathrm{cm}$ and $1 \mathrm{phr}$ of CNT, when epoxidized natural rubber (ENR) was CNT filled instead of using unmodified NR. This is due to the polarity of oxirane rings in the ENR [2]. Both physical and chemical interactions occur between ENR and CNT surfaces.
When the nanotubes were restricted by these interactions their re-agglomeration in the rubber matrix after compounding, controlled by depletion forces, was eventually prevented. Thus, CNT can possibly form infinite conductive pathways in the rubber matrix and carry electrons throughout the material. This gives high $\Theta_{\max }$ with low $\varphi_{c}$ in the ENR/CNT composites, relative to CNT filled unmodified NR composites, while the three-dimensional CNT networks partly rely on electron tunneling. For comparison, the $\Theta_{\max }$ of pure CNT is approximately $10^{5} \mathrm{~S} / \mathrm{cm}$ [3], that of NR/CNT is about $10^{-2} \mu \mathrm{S} / \mathrm{cm}$, and ENR/CNT gives approximately $10 \mu \mathrm{S} / \mathrm{cm}$. The difference between $\Theta_{\max }$ of CNT and rubber is huge, approximately

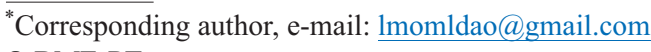
(C) BME-PT 
$10^{10} \mathrm{~S} / \mathrm{cm}$. The lower $\Theta_{\max }$ in NR composites might be attributed to the CNT particles being covered by non-polar rubber molecules, so electrons cannot tunnel between the conductive nanotubes. To enhance the electrical conductivity and other related properties, the gaps between CNT particles need to be bridged. Hence, a secondary filler such as carbon black (CB), in the form of furnace black or conductive carbon black (CCB), was recently incorporated to CNT filled composites for reducing the gaps between CNT bundles [4]. It was found that addition of 1.5/1.0 phr of CCB/CNT in NR composite increased $\Theta_{\max }$ to approximately $1 \mathrm{kS} / \mathrm{cm}$, but reduced $\varphi_{\mathrm{c}}$ to $1 \mathrm{phr}$ of CNT [4]. Also, at the optimal conductivity, about $2 \mathrm{~nm}$ gaps were found for the fillers [4], enabling tunneling of electrons between the CNT bundles. However, the dielectric constant of the composites was still high in the NR composites with CNT contents over the percolation threshold concentration. This correlated to the high conductivity of the composites on reaching the saturated part of conductivity response after percolation threshold. This means that the rubber barriers still had strong effects on conductivity. Therefore, the conductivity of the composites could be enhanced and the dielectric constant could be reduced if the CNT forms threedimensional networks in the rubber matrix, with minimal gaps between the CNT bundles.

Silane coupling agent, particularly bis(triethoxysilylpropyl)tetrasulfide (TESPT), has been long applied to enhance filler dispersion (CB, CNT and silica) in NR and ENR matrices [5]. It was found that incorporation of TESPT significantly improved dispersion of CNT in NR and ENR matrices and improved the optimal conductivity by about two orders of magnitude relative to composites without TESPT [6]. It was claimed that the ethoxy groups on TESPT interacted with some functional groups on CNT surfaces by condensation reactions, while the sulfur atoms bonded to the $\mathrm{C}=\mathrm{C}$ bonds of rubber. The interactions in CNT-TESPT-rubber limited the movement of CNT and its re-agglomeration after compounding and vulcanizing. This effectively improved CNT dispersion and also the electrical conductivity of the rubber composites. However, only limited information is available regarding effects of $\mathrm{CNT} / \mathrm{CCB}$ hybrid filler. Thus, an investigation of silane coupling agent in CNT/CCB hybrid filler filled NR and ENR composites is warranted, to potentially improve the electrical performance of these composites.
Therefore, in the present work, NR and ENR composites with CNT and CCB hybrid fillers were prepared in an internal mixer and on a two-roll mill. A silane coupling agent, namely bis(triethoxysilylpropyl)tetrasulfide (TESPT), was used as the coupling agent bridging $\mathrm{CCB}$ and $\mathrm{CNT}$ to the rubber molecules. This was expected to improve the filler dispersion. It is noted that the in-situ functionalization of TESPT on filler surfaces was performed by mixing at temperatures elevated to $130-150{ }^{\circ} \mathrm{C}$. The main aim was to study the roles of silane coupling agent and polarity of rubber molecules regarding electrical and other related properties of the composites. The thermal-mechanical properties, electrical conductivity, morphological characterization and cure characteristics of rubber composites were investigated. In addition, effects of TESPT on electrical conductivity of NR and ENR composites were statistically analyzed using ANOVA.

\section{Experimental}

\subsection{Materials}

Two types of natural rubber were used: natural rubber (NR) and epoxidized natural rubber (ENR). NR as air dried sheets (ADS) was manufactured by a local factory operated by Na Born Farmer Cooperation (Nakorn Si Thammarat, Thailand). Also, ENR with 25 mol\% epoxide (i.e., ENR-25) was manufactured by Muang Mai Guthrie Public Company Limited (Surat Thani, Thailand). In addition, high ammonia NR latex with $60 \%$ dry rubber content (DRC) was used to determine the contact angle. It was supplied by Von Bundit Co., Ltd. (Surat Thani, Thailand). Diethylene glycol and formamide were used to measure wetting ability of rubbers and fillers, and they were manufactured by Merck KGaA (Darmstadt, Germany). The multi-wall carbon nanotubes (NC7000) with $9.5 \mathrm{~nm}$ diameter, ca. $1.5 \mu \mathrm{m}$ length, and $90 \%$ purity, were manufactured by Nanocyl S. A. (Sambreville, Belgium). The conductive carbon black (CCB), Vulcan XC72 with primary particle diameter of about $30 \mathrm{~nm}$, was manufactured by Cabot Corporation (Texas, USA). Other ingredients used in the rubber compounding formulation are summarized in Table 1.

\subsection{Preparation of rubber composites}

The NR and ENR vulcanizates reinforced by CCB, CNT and CNT/CCB hybrid fillers without and with TESPT silane coupling agent were carefully prepared by first mixing in an internal mixer $\left(\right.$ size $78 \mathrm{~cm}^{3}$, 
Table 1. Chemical ingredients and formulations of the rubber compounds filled with CCB, CNT or CNT/CCB hybrid filler.

\begin{tabular}{|l|l|c|}
\hline \multicolumn{1}{|c|}{ Chemical } & \multicolumn{1}{c|}{ Supplier } & \multicolumn{1}{c|}{$\begin{array}{c}\text { Content } \\
\text { [phr] }\end{array}$} \\
\hline Rubbers & See in text & 100 \\
\hline Stearic acid & Imperial Chemical Co. Ltd., Pathum Thani, Thailand & 1 \\
\hline Zinc oxide (ZnO) & Global Chemical Co. Ltd., Samut Prakarn, Thailand & 5 \\
\hline $2,2^{\prime}$-Dithiobis-(benzothiazole) (MBTs) & Flexsys Inc., Brussels, Belgium & 1 \\
\hline Sulfur & Ajax Chemical Co. Ltd., Samut Prakarn, Thailand & 2.5 \\
\hline CNT & Nanocyl S.A., Belgium & Varied $0-7$ \\
\hline CCB & Cabot Corporation, Texas, USA & Varied $0-15$ \\
\hline Bis(triethoxysilylpropyl)tetrasulfide (TESPT) & Sigma-Aldrich Co. Ltd. Dorset, United Kingdom & $0.06 \mathrm{~mL} / \mathrm{g}$ of CNT \\
\hline
\end{tabular}

Brabender VR GmbH\&Co. KG, Duisburg, Germany) under temperatures controlled to $130-150{ }^{\circ} \mathrm{C}$ and a rotor speed of $60 \mathrm{rpm}$. It is noted that the rubber and fillers were first mixed together for about $5 \mathrm{~min}$. Then, the TESPT was added and continuously mixed for another $6 \mathrm{~min}$, before dumping the rubber compound from the mixing chamber. The compounds were then conditioned at room temperature for approximately $2 \mathrm{~h}$ and thereafter mixed with other chemical ingredients, including zinc oxide $(\mathrm{ZnO})$, stearic acid, accelerator (MBTS) and sulfur, in an internal mixer at $60^{\circ} \mathrm{C}$ using the same rotor speed. In addition, a gum rubber compound (i.e., without fillers and TESPT) was also prepared by the same procedure for comparison purposes. The compound was eventually passed through the $1 \mathrm{~mm}$ nip of the two-roll mill (Chareon Tut Co. Ltd., Samut Prakan, Thailand) several times before conditioning at room temperature in a desiccator for at least $24 \mathrm{~h}$. Finally, rubber vulcanizate sheets with dimensions $150 \times 160 \times 2 \mathrm{~mm}$ were prepared by compression molding (Charoen Tut Co. Ltd., Samut Prakan, Thailand) at $160{ }^{\circ} \mathrm{C}$, using $90 \%$ cure times based on rheometer curves at a frequency of $1.67 \mathrm{~Hz}$ and strain amplitude of $1^{\circ}$ arc at $160^{\circ} \mathrm{C}$. It is noted that the rubber vulcanizates with $\mathrm{CCB}, \mathrm{CNT}$, CNT/CCB hybrid filler without and with TESPT were labeled as ' $X-\mathrm{CCB}_{\mathrm{y}}$ ', ' $X-\mathrm{CNT}_{\mathrm{y}}$ ', ' $X-\mathrm{CNT}_{\mathrm{y}} / \mathrm{CCB}_{\mathrm{y}}$ ' and ' $X$-CNT $\mathrm{CN}_{\mathrm{Si}-\mathrm{y}} / \mathrm{CCB}_{\mathrm{y}}$ ', respectively, where $X$ indicates the type of rubber (i.e., NR and ENR), $y$ refers to the filler content in parts per hundred rubber [phr], and $\mathrm{Si}$ indicates vulcanizates with TESPT silane coupling agent.

\section{Characterization}

\subsection{Attenuated total reflection Fourier transform infrared spectroscopy (ATR-FTIR)}

The ATR-FTIR spectra were determined by the Thermo Nicolet Avatar 360 FTIR (Thermo Electron
Corporation, Madison, USA), with $4 \mathrm{~cm}^{-1}$ resolution and 64 scans per sample. The instrument was equipped with a germanium ATR crystal probe. In this work, the functional groups in vulcanized and un-vulcanized composites were investigated. That is, the unvulcanized rubber composites were studied to assess the chemical interactions of the components that took place during mixing and compression. The samples were therefore prepared without curatives but using the same mixing and compression molding processes as on preparing the vulcanized samples. To characterize the un-vulcanized samples, they were first soaked in cyclohexane for $72 \mathrm{~h}$ in order to separate the insoluble and soluble parts. The rubber content in the soluble phase was precipitated with ethanol, filtered, and then dried at $40^{\circ} \mathrm{C}$ until constant weight, and then characterized by the ATR-FTIR. On the other hand, the insoluble part was directly dried at $40^{\circ} \mathrm{C}$ and then examined by ATR-FTIR.

\subsection{Contact angle}

Contact angles of rubber and filler samples were measured according to the Owens and Kaelble method [7] using a contact angle analyzer (SL200KS, Kino industry Co., Ltd., Georgia, USA). Three liquids with different surface tensions were used, namely water, diethylene glycol, and formamide. Firstly, about $1 \mu \mathrm{L}$ of a liquid was dropped on a smooth surface of rubber or filler samples, with 10 replicates done at room temperature. It is noted that the NR sample was prepared by casting high concentration ammonia (HA type) NR on a glass plate and drying at $50^{\circ} \mathrm{C}$ until constant weight. In addition, the NRTESPT sample was prepared by mixing NR latex and TESPT by stirring at $300 \mathrm{rpm}$ for about $30 \mathrm{~min}$ before casting and drying. Contact angles of the ENR and ENR-TESPT cases were also measured directly on the dried rubber sheets. It is noted that the ENRTESPT was prepared by mixing ENR and TESPT in 
an internal mixer at $130^{\circ} \mathrm{C}$ for $6 \mathrm{~min}$. In addition, the filler samples were prepared by methods described elsewhere [8]. That is, about $4 \times 1 \mathrm{~cm}$ strip of doublesided adhesive tape was immersed in the filler powder and then gently removed, repeating until it was uniformly coated by the filler, without applying pressure. Furthermore, any un-bonded powder on the tape was blown off with nitrogen gas before measuring the contact angles.

\subsection{Payne effect}

The Payne effect was determined by using a rubber process analyzer (RPA) (Alpha Technologies, Akron, USA) in order to examine the state of filler-filler interaction. The test was performed by measuring the storage shear modulus $\left(G_{0}\right)$ of each filled rubber compound under shear deformation with strain amplitudes in the range $0.56-100 \%$ at a fixed oscillation frequency of $1 \mathrm{~Hz}$ at $100^{\circ} \mathrm{C}$. The Payne effect recorded is the difference in storage moduli at the strain amplitudes 0.56 and $100 \%$.

\subsection{Temperature scanning stress relaxation (TSSR)}

The TSSR measurements were performed using a TSSR meter (Brabender ${ }^{\mathbb{B}}$ GmbH\&Co. KG, Duisburg, Germany) in order to characterize physical and chemical interactions of rubber molecules, filler surfaces and silane coupling agent. Here, dumbbell shaped specimens (type 5A, ISO 527) were prepared and placed in the TSSR sample holder in the test chamber. Then, $50 \%$ strain was applied at $23^{\circ} \mathrm{C}$ and the sample was conditioned at this temperature and at constant $50 \%$ extension for $2 \mathrm{~h}$, to allow isothermal short-time relaxations [9]. After that, in non-isothermal testing the temperature was raised from 23 to $220^{\circ} \mathrm{C}$ at a constant $2{ }^{\circ} \mathrm{C} / \mathrm{min}$ heating rate $(v)$. Then, the relaxation spectrum $(H(T))$ was automatically calculated from the relation of relaxation modulus $(E(T))$ and temperature ( $T)$, as shown in Equation (1) [10]:

$$
H(T)=-T\left[\frac{\mathrm{d} E(T)}{\mathrm{d} T}\right]_{\mathrm{v}=\text { const }}
$$

\subsection{Electrical properties}

Electrical properties of unfilled and filled rubber vulcanizates, in terms of resistance $\left(R_{\mathrm{p}}\right)$, capacitance $\left(C_{\mathrm{p}}\right)$ and dissipation factor $(\tan \delta)$, were measured at room temperature using an LCR meter (Hioki IM 3533, Hioki E.E. Corporation, Nagano, Japan) in the frequency range from 1 to $10^{5} \mathrm{~Hz}$. The sample was first placed between two parallel plates of the dielectric test fixture (16451B dielectric test fixture, Test Equipment Solutions Ltd., Berkshire, United Kingdom) with $5 \mathrm{~mm}$ electrode diameter. The electrical conductivity $(\sigma)$, and dielectric constant $\left(\varepsilon^{\prime}\right)$ were calculated using Equations (2) and (3), respectively [11]:

$$
\begin{aligned}
\sigma & =\frac{1}{\rho}=\frac{d}{\left(R_{\mathrm{p}}\right) A} \\
\varepsilon^{\prime} & =\frac{C_{\mathrm{p}}(d)}{A\left(\varepsilon_{0}\right)}
\end{aligned}
$$

where $d$ and $A$ refer to the sample thickness and the area of an electrode, respectively. The factor $\rho$ is the volume resistivity, i.e., the reciprocal of conductivity. The parameter $\varepsilon_{0}$ is the dielectric constant of the free space, which is $8.854 \cdot 10^{-12} \mathrm{~F} / \mathrm{m}$.

\subsection{Bound rubber content and bound rubber layer thickness}

Bound rubber content and bound rubber layer thickness in the rubber composites were estimated by the swelling method. The un-vulcanized samples were initially cut into small pieces and inserted into a cage with 300 mesh sieves. The samples were then immersed and soaked in toluene for about $72 \mathrm{~h}$, renewing the toluene every $24 \mathrm{~h}$. The samples were removed from toluene and then dried at $105^{\circ} \mathrm{C}$ for at least $24 \mathrm{~h}$ before immersing in toluene again for another $72 \mathrm{~h}$ at room temperature, either in the normal state or in ammonia atmosphere [5], renewing of toluene every $24 \mathrm{~h}$. This was to cleave the physical linkages between rubber and filler surfaces. Finally, the samples were removed from the solvent, dried at $105^{\circ} \mathrm{C}$ for at least $24 \mathrm{~h}$ and then weighted. The bound rubber content was calculated using Equation (4) [12]:

Bound rubber content $[\%]=\frac{W_{\mathrm{fg}}-W_{\mathrm{f}}}{W_{\mathrm{p}}}$

where $W_{\mathrm{f}}$ and $W_{\mathrm{p}}$ are the weights of filler and rubber in the specimen, respectively, and $W_{\mathrm{fg}}$ is weight of filler with absorbed bound rubber after toluene extraction.

In addition, the bound layer thickness was determined by immersing the samples in toluene for 7 days, renewing the toluene every $24 \mathrm{~h}$. Then, the samples were filtered, weighed, dried at $105^{\circ} \mathrm{C}$ for at least $24 \mathrm{~h}$, 
and weighed again. The bound layer thickness $(\delta)$ was calculated from Equation (5) [13]:

$\delta=\frac{m_{2}-m_{1}\left(C_{\mathrm{f}}\right)}{\rho_{\mathrm{R}} m_{1}\left(C_{\mathrm{f}}\right) S_{\mathrm{f}}}$

where $m_{1}$ is mass of the rubber compound before extracting, $m_{2}$ is mass of the rubber-filler gel consisting of non-dissolving bound rubber and filler. Parameters $C_{\mathrm{f}}$ and $S_{\mathrm{f}}$ are the mass concentration and the specific surface area of filler in the composites, respectively, and $\rho_{R}$ refers to the density of the rubber matrix.

\subsection{Morphological properties}

The morphological properties of the NR and ENR vulcanizates with CNT/CCB hybrid filler, with and without TESPT, were characterized by scanning electron microscopy (SEM) using ZeissSupra-40 VP (Carl Zeiss Microscopy GmbH, Oberkochen, Germany). Each specimen was first cryogenically fractured in liquid nitrogen to create a fresh cross-sectional surface. Then, the samples were sputter-coated with a thin layer of gold under vacuum before SEM examination. Furthermore, the samples were also characterized by transmission electron microscopy (TEM), (Jeol JEM 2010, Jeol Ltd., Tokyo, Japan) using $200 \mathrm{kV}$ accelerating voltage. The ultrathin slices (about $80-90 \mathrm{~nm}$ ) were prepared by diamond knife of the RMC-MT-X ultramicrotome (Boeckeler Instruments, Inc., Arizona, USA) at cryogenic $-100^{\circ} \mathrm{C}$ temperature. The thin samples were then mounted on 200 mesh copper grids before characterizing by TEM.

\subsection{Cure characteristics}

Cure characteristics of the pure NR and ENR and their composites, in terms of scorch time, cure time and torque difference, were determined by using an oscillating disc rheometer (ODR 2000, Monsanto Co. Ltd. Ohio, USA). The measurement was performed at a frequency of $1.67 \mathrm{~Hz}$ and strain amplitude of
1 arc degree at $160^{\circ} \mathrm{C}$. Scorch and cure times and other curing properties, such as torque difference, were determined. It is noted that the scorch time $\left(t_{\mathrm{sl}}\right)$ refers to the time at which the torque has increased by $1 \mathrm{dNm}$ from the minimum torque. The $t_{90}$ is the $90 \%$ cure time of the sample, and $M_{\mathrm{H}}-M_{\mathrm{L}}$ is the torque difference between maximum $\left(M_{\mathrm{H}}\right)$ and minimum $\left(M_{\mathrm{L}}\right)$ torques.

\section{Results and discussion \\ 4.1. Interactions of rubber, silane coupling agent and filler surfaces}

Chemical linkages might occur in the rubber compound and vulcanizates by reactions of rubber, silane coupling agent (TESPT) and filler surfaces (CCB and CNT) during mixing and curing. These reactions could be verified by ATR-FTIR technique, and the ATR-FTIR spectra of pure NR and ENR together with their vulcanizates with $\mathrm{CCB}, \mathrm{CNT}, \mathrm{CNT} / \mathrm{CCB}$, without and with TESPT silane coupling agent, are shown in Figure 1. In addition, the italic number in parentheses refers to the peak intensity ratio $\left(\omega_{\text {pir }}\right)$, which is the ratio of a peak to the reference peak for asymmetric methylene $\mathrm{C}-\mathrm{H}$ stretching vibrations at $2963 \mathrm{~cm}^{-1}$. The peak assignments for the FTIR spectra in Figure 1 are summarized in Table 2. It is seen that the NR and ENR spectra showed the principal peaks for C-C stretching vibrations at $832 \mathrm{~cm}^{-1}$ [14], $\mathrm{C}-\mathrm{H}$ bending vibrations at $1008 \mathrm{~cm}^{-1}$ [14], symmetric and asymmetric $\mathrm{C}-\mathrm{H}$ stretching vibrations at 1375 and $1449 \mathrm{~cm}^{-1}$ [14], C-O stretching vibrations of zinc stearate at $1538 \mathrm{~cm}^{-1}$ (due to the reaction between $\mathrm{ZnO}$ and stearic acid) $[14,15], \mathrm{C}=\mathrm{C}$ stretching vibrations at $1660 \mathrm{~cm}^{-1}$, and asymmetric $\mathrm{C}-\mathrm{O}-\mathrm{C}$ stretching vibrations of oxirane rings in the ENR at $870 \mathrm{~cm}^{-1}[14,15]$. Furthermore, additional absorption peaks were observed in the spectrum of NR-CNT $\mathrm{Si}_{\mathrm{S}} /$ $\mathrm{CCB}$ vulcanizate at the wavenumbers 1077 and $1126 \mathrm{~cm}^{-1}$, which were assigned to the $\mathrm{Si}-\mathrm{O}-\mathrm{Si}$ and

Table 2. Peak Assignments of the ATR-FTIR spectra in Figures 1 and 3.

\begin{tabular}{|l|l|}
\hline $\begin{array}{c}\text { Wave number } \\
{\left[\mathbf{c m}^{-\mathbf{1}}\right]}\end{array}$ & \multicolumn{1}{c|}{ Assignment } \\
\hline 832 & $=\mathrm{C}-\mathrm{H}$ out of plane bending vibrations \\
\hline 870 & $\mathrm{C}-\mathrm{O}$ stretching vibrations of oxirane ring \\
\hline 1008 & $\mathrm{C}-\mathrm{H}$ bending vibration \\
\hline 1077 and 1126 & $\mathrm{Si}-\mathrm{O}-\mathrm{Si}$ and $\mathrm{Si}-\mathrm{O}-\mathrm{C}$ asymmetric stretching vibrations \\
\hline 1375 and 1449 & $\mathrm{Symmetric}$ and asymmetric $\mathrm{C}-\mathrm{H}$ stretching vibrations \\
\hline 1538 & $\mathrm{C}=\mathrm{O}$ stretching vibrations of zinc stearate \\
\hline 1660 & $\mathrm{C}=\mathrm{C}$ stretching vibrations \\
\hline
\end{tabular}



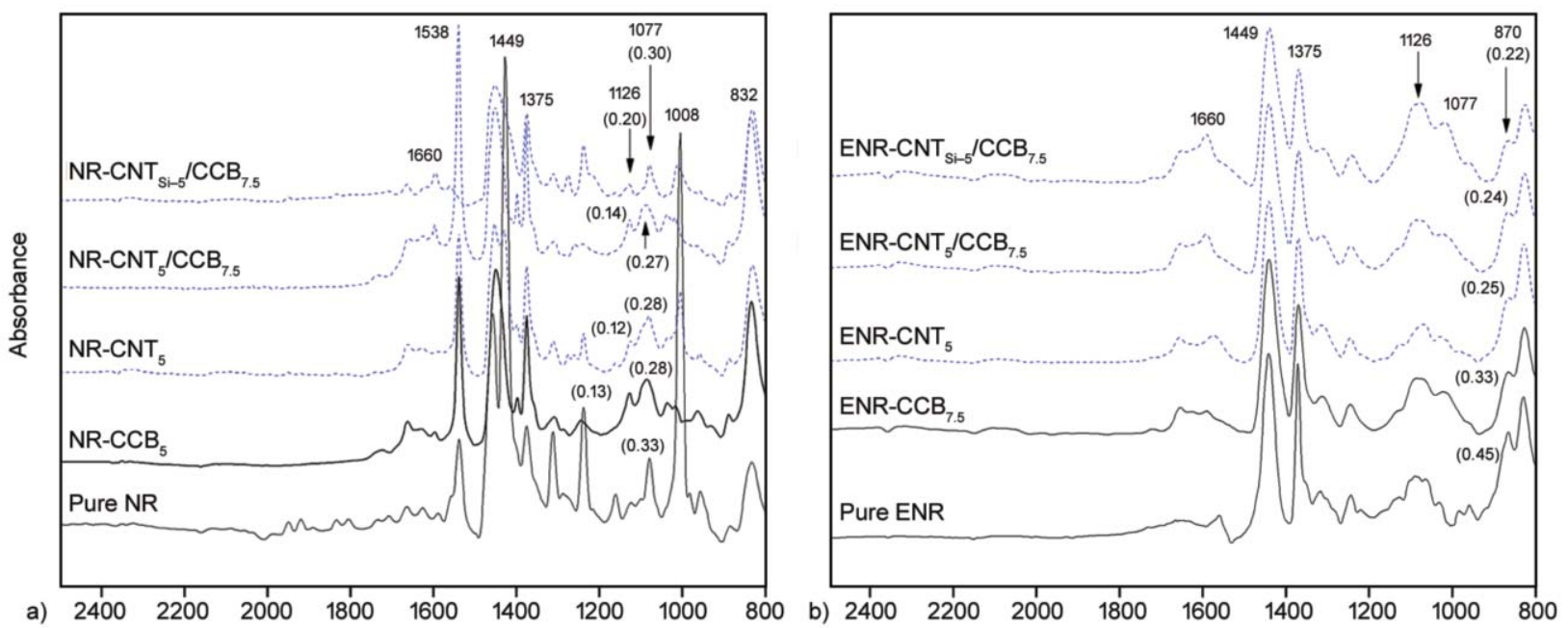

Figure 1. ATR-FTIR spectra of pure NR and CCB, CNT and CNT/CCB hybrid filler filled NR vulcanizates with and without TESPT (a); and pure ENR together with CCB, CNT and CNT/CCB hybrid filler filled ENR with and without TESPT (b) (the italic numbers are the peak intensity ratios with respect to the reference peak at $2963 \mathrm{~cm}^{-1}$ from asymmetric methylene $\mathrm{C}-\mathrm{H}$ stretching vibrations).

$\mathrm{Si}-\mathrm{O}-\mathrm{C}$ asymmetric stretching vibrations, respectively $[14,15]$. In Figure 1a, it is clearly seen that the $\omega_{\text {pir }}$ at wave numbers 1077 and $1126 \mathrm{~cm}^{-1}$ increased significantly with the addition of TESPT. This affirms the silanization reactions among NR, TESPT and CNT/CCB. In particular the absorption peak at $1126 \mathrm{~cm}^{-1}$ reveals interaction to form $\mathrm{Si}-\mathrm{O}$ in the CNT/CCB-grafted TESPT and the $\mathrm{C}-\mathrm{C}$ in the NR [16], with proposed reaction mechanisms shown in Figure 2. According to the polar functional groups on the CNT ( $2-5 \%$ of hydroxyl and carboxylic groups $[2,15,17])$ and CCB surfaces [18], the condensation reactions between TESPT and CCB together with CNT surfaces possibly propagated when

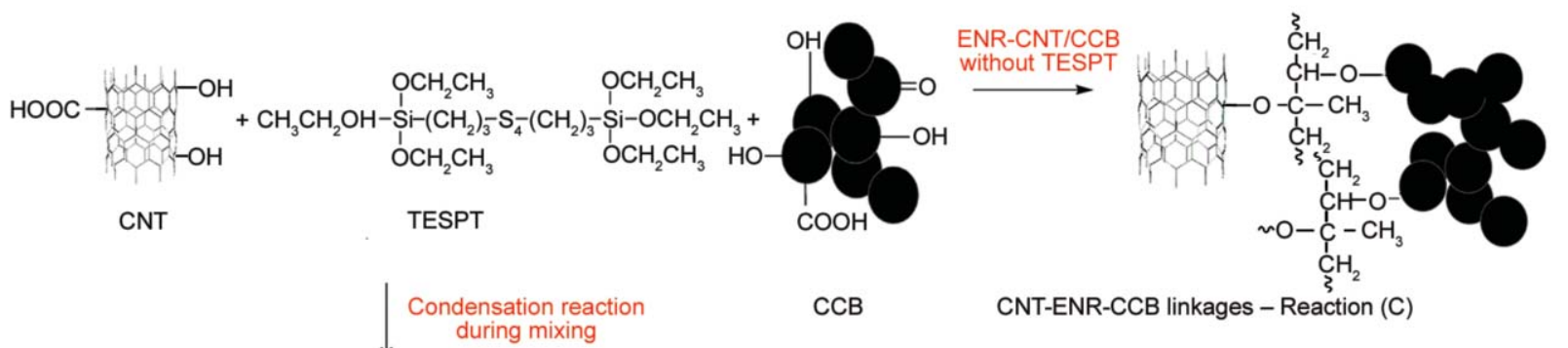
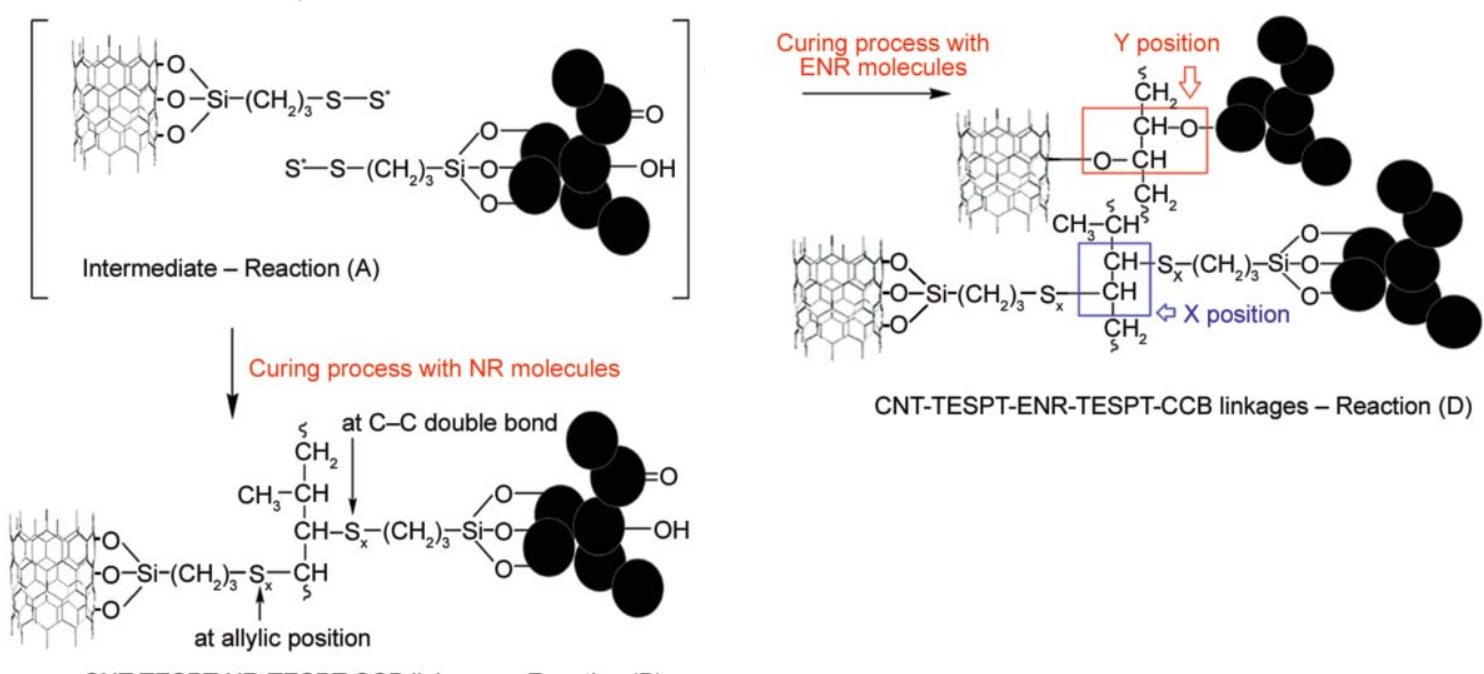

CNT-TESPT-NR-TESPT-CCB linkages - Reaction (B)

Figure 2. Proposed condensation reaction mechanisms among TESPT and CNT/CCB (Reaction (A)), NR, CNT/CCB and TESPT (Reaction (B)), ENR and CNT/CCB (Reaction (C)) and ENR, CNT/CCB and TESPT (Reaction (D)). 
the NR-CNT/CCB compound was mixed with TESPT in an internal mixer under high temperature and shearing action (as indicated in Reaction (A), Figure 2) [16-18]. In addition, during curing the active sulfur atoms on CNT/CCB-grafted TESPT are capable of bonding to $\mathrm{NR}$ molecules through $\mathrm{C}=\mathrm{C}$ bonds and with $\mathrm{CH}_{2}$ in the allylic position (Reaction (B)) $[15,16]$. In Figure $1 b$, it is clearly seen that the $\omega_{\text {pir }}$ at the wavenumber of $870 \mathrm{~cm}^{-1}$ of pure ENR and ENR vulcanizates significantly decreased with addition of $\mathrm{CCB}, \mathrm{CNT}, \mathrm{CNT} / \mathrm{CCB}$, or in particular the addition of CNT/CCB with TESPT silane coupling agent. This might be attributed to the oxirane rings in ENR that are easily broken to form diol groups during mixing at high temperature and shear $[2,15]$. These diol groups are capable of reacting with the polar functional groups on CCB and CNT surfaces ((Reaction $(C)$ in Figure 2). This might be the rationale for reduced peak intensity at $870 \mathrm{~cm}^{-1}$ (i.e., asymmetric $\mathrm{C}-\mathrm{O}-\mathrm{C}$ stretching vibrations of oxirane rings) after addition of $\mathrm{CCB}$ and CNT. In addition, this peak is strongly reduced by addition of the $\mathrm{CNT} / \mathrm{CCB}$ hybrid filler, owing to the high filler volume fraction and hence strong interactions in the composites system. On the other hand, the lowest $\omega_{\text {pir }}$ value at $870 \mathrm{~cm}^{-1}$ was observed after addition of CNT/CCB with TESPT. This might be due to the improved dispersion of CNT and CCB with TESPT. That is, the ethoxy groups in TESPT molecules reacted with the functional groups on $\mathrm{CCB}$ and CNT surfaces by condensation (Reaction (A)). Then, the sulfur atoms were bonded to $\mathrm{C}=\mathrm{C}$ bonds at $\mathrm{X}$ position (Reaction (D) in Figure 2) and the remaining ethoxy groups from condensation might directly react with diol groups in ENR at Y position (Reaction (D) in Figure 2). Thus, stronger chemical interactions between rubber molecules and filler surfaces were possible with the TESPT silane coupling agent. This reduced $\omega_{\text {pir }}$ at $870 \mathrm{~cm}^{-1}$ to approximately 0.22 , compared to 0.45 for the pure ENR.

To analyze the chemical interactions between the epoxide groups in ENR and the functional groups on filler surfaces, the ATR-FTIR spectra of pure ENR, ENR-CCB, ENR-CNT and ENR-CNT/CCB without and with TESPT silane (without the curing agents: accelerator and sulfur) after extraction with cyclohexane were determined, with the results shown in Figure 3. It is seen that $\omega_{\text {pir }}$ for gum ENR is 0.47 but for the corresponding vulcanizate it is 0.45 (Figure 1).

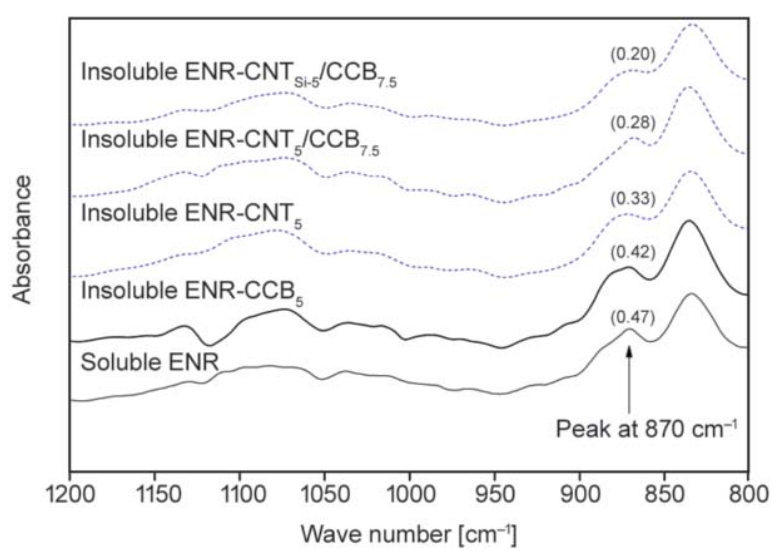

Figure 3. ATR-FTIR spectra of un-vulcanized soluble pure ENR and insoluble ENR with CCB, CNT, CNT/ CCB hybrid filler with and without TESPT after extraction with cyclohexane for $72 \mathrm{~h}$ (the italic numbers are the peak intensity ratios with respect to the reference peak at $2963 \mathrm{~cm}^{-1}$ ).

Therefore, the content of epoxirane rings in ENR did not change significantly when curative was added. However, the ENR-CCB and ENR-CNT compound samples were separated to two parts: the soluble and insoluble fractions. The soluble part was coagulated by ethanol and dried to obtain a rubber sheet, which was then characterized by ATR-FTIR. It was found that the $\omega_{\text {pir }}$ was the same as for the gum ENR (i.e., $\left.\omega_{\text {pir }}=0.47\right)$. This means that this part is gum ENR, un-reacted with filler surfaces. On the other hand, the insoluble parts of ENR-CCB and ENR-CNT contain reaction products from interactions of ENR and filler (i.e., CCB and CNT). That is, the $\omega_{\text {pir }}$ at $870 \mathrm{~cm}^{-1}$ was significantly reduced for ENR-CCB and ENR-CNT, from 0.45 (in ENR vulcanizate) and 0.47 (in soluble ENR fraction) to 0.42 and 0.33 , respectively. This confirms the chemical interactions between ENR molecules and filler surfaces, as proposed in Figure 2 (Reaction $(\mathrm{C})$ ). In addition, the $\omega_{\text {pir }}$ for ENR-CNT/CCB without and with TESPT is comparatively low, in particular with TESPT at 0.20. This means that the chemical interactions among ENR, CCB and CNT in the presence of TESPT were extensive. That is, chemical linkages of ENRCNT/CCB-TESPT were formed in the ENR compound, as described in Figure 2 (Reaction (D)). Therefore, the condensation and silanization reactions among rubber molecules (NR and ENR), fillers (CNT and CCB) and silane coupling agent (TESPT) were favorable and improved filler dispersion in the NR and ENR vulcanizates. 


\subsection{Filler dispersion}

The dispersion and localization of fillers in rubber matrix can be roughly determined by the intrinsic properties of the individual rubber and filler, namely by their solubilities and wetting abilities with various non-polar and polar solvents. Based on the Owens and Kaelble theory, the surface energy $(\gamma)$, dispersive $\left(\gamma^{\mathrm{d}}\right)$ and polar $\left(\gamma^{\mathrm{p}}\right)$ interactions and interfacial energies $\left(\gamma_{\mathrm{sl}}\right)$ could be determined from Equations (6) and (7) [19]:

$$
\begin{aligned}
& (1+\cos \theta) \gamma_{1}=2\left[\left(\gamma_{\mathrm{s}}^{\mathrm{d}} \cdot \gamma_{1}^{\mathrm{d}}\right)^{0.5}+\left(\gamma_{\mathrm{s}}^{\mathrm{p}} \cdot \gamma_{\mathrm{l}}^{\mathrm{p}}\right)^{0.5}\right] \\
& \gamma_{s \mathrm{l}}=\gamma_{\mathrm{s}}+\gamma_{1}-2\left[\left(\gamma_{\mathrm{s}}^{\mathrm{d}} \cdot \gamma_{\mathrm{l}}^{\mathrm{d}}\right)^{0.5}+\left(\gamma_{\mathrm{s}}^{\mathrm{p}} \cdot \gamma_{1}^{\mathrm{p}}\right)^{0.5}\right]
\end{aligned}
$$

where, $\gamma_{s}, \gamma_{s}^{\mathrm{d}}, \gamma_{\mathrm{s}}^{\mathrm{p}}\left(\gamma_{1}, \gamma_{1}^{\mathrm{d}}, \gamma_{1}^{\mathrm{p}}\right)$ are total surface energy, and surface energy of the dispersive and the polar parts for the sample (the liquid), respectively. Parameter $\theta$ is the contact angle of the sample with water $\left(\mathrm{H}_{2} \mathrm{O}\right)$, diethylene glycol $\left(\mathrm{C}_{2} \mathrm{H}_{6} \mathrm{O}_{2}\right)$ or formamide $\left(\mathrm{CH}_{3} \mathrm{NO}\right)$. These can be computed from the known values $\gamma^{\mathrm{d}}{ }_{\mathrm{H}_{2} \mathrm{O}}=19.90 \mathrm{mN} / \mathrm{m}$ and $\gamma^{\mathrm{p}} \mathrm{H}_{2} \mathrm{O}=52.20 \mathrm{mN} / \mathrm{m}$, $\gamma^{\mathrm{d}} \mathrm{C}_{2} \mathrm{H}_{6} \mathrm{O}_{2}=35.91 \mathrm{mN} / \mathrm{m}$ and $\gamma^{\mathrm{p}} \mathrm{C}_{2} \mathrm{H}_{6} \mathrm{O}_{2}=9.30 \mathrm{mN} / \mathrm{m}$, and $\gamma^{\mathrm{d}} \mathrm{CH}_{3} \mathrm{NO}=23.50 \mathrm{mN} / \mathrm{m}$ and $\gamma^{\mathrm{p}} \mathrm{CH}_{3} \mathrm{NO}=$ $33.40 \mathrm{mN} / \mathrm{m}[7,20]$. In addition, the parameter $\gamma_{\mathrm{sl}}$ refers to the interfacial energies of rubber and $\mathrm{CCB}$ or rubber and CNT. It is noted that these values for the CNT/CCB hybrid filler could not be determined since the real contact angle of the mixed fillers on an adhesive tape could not be identified.

Table 3 shows the wetting abilities (i.e., total surface energy $(\gamma)$, the dispersive $\left(\gamma^{\mathrm{d}}\right)$ and the polar interactions $\left.\left(\gamma^{\mathrm{p}}\right)\right)$ of fillers, rubbers, rubbers with silane coupling agent and the composites with and without TESPT, which were calculated from Equations (6) and (7). It is seen that the ENR composites with CCB and CNT (i.e., ENR-CCB and ENR-CNT) had higher interfacial energies $\left(\gamma_{\mathrm{sl}}\right)$ than those with NR. This might be related to the polarity of ENR that enables interactions with the functional groups on $\mathrm{CCB}$ and CNT surfaces. Furthermore, the interfacial energy of NR-CCB, NR-CNT, ENR-CCB and ENRCNT was significantly increased by addition of TESPT, as seen in NR/TESPT-CCB, NR/TESPTCNT, ENR/TESPT-CCB and ENR/TESPT-CNT. Therefore, TESPT enhances the polarity of the rubber molecules, the polar interactions $\left(\gamma^{\mathrm{p}}\right)$ and the surface polarity $(S P)$ in NR-TESPT and ENR-TESPT to higher levels than in gum NR and ENR, respectively, where the NR-TESPT and ENR-TESPT designate the pure NR and ENR with TESPT. Thus, chemical interactions between rubber molecules and filler surfaces were improved by the addition of silane coupling agent. Furthermore, it is clearly seen that the CNT displayed higher interfacial energy than the $\mathrm{CCB}$ in both types of rubber matrix, both with and without TESPT. This mainly relates to the shape and size differences of the fillers. That is, the CNT has high aspect ratio and larger specific surface area supporting more interactions with the rubber matrix than the CCB. This might be also the reason why the CNT had good dispersion and could easily form filler networks at sufficiently low concentrations. On the other hand, high $\mathrm{CCB}$ concentrations gave strong agglomeration due to lower interfacial energy with the rubber matrix. Therefore, the CNT plays the key role in improving rubber composite properties with CNT/ CCB hybrid filler. Also, the addition of TESPT improved filler dispersion, which might enhance the reinforcement efficiency of CCB and CNT.

Dynamic properties were also used to estimate the degree of filler-filler interactions in the composites, in terms of the relationship between storage modulus and strain amplitude and the Payne effect shown in Figure 4. In Figure 4a, it was found that the ENR composites with CNT, CCB and CNT/CCB hybrid filler showed higher storage moduli than the NR composites. This is due to the improvement of the

Table 3. Total surface energy $(\gamma)$, the dispersive $\left(\gamma^{\mathrm{d}}\right)$ and the polar interactions $\left(\gamma^{\mathrm{p}}\right)$, the surface polarity $\left(S P_{\mathrm{s}}\right)$, as well as the interfacial energies $\left(\gamma_{\mathrm{sl}}\right)$ of the pure rub-

\begin{tabular}{|c|c|c|c|c|}
\hline Sample & $\begin{array}{c}\gamma \\
{[\mathrm{mN} / \mathrm{m}]}\end{array}$ & $\begin{array}{c}\gamma^{\mathrm{d}} \\
{[\mathrm{mN} / \mathrm{m}]}\end{array}$ & $\begin{array}{c}\gamma^{\mathrm{p}} \\
{[\mathrm{mN} / \mathrm{m}]}\end{array}$ & $\begin{array}{l}{ }^{*} S P_{\mathrm{s}} \\
{[\%]}\end{array}$ \\
\hline Pure NR & 21.50 & 17.20 & 4.30 & 20.00 \\
\hline Pure ENR & 24.74 & 18.52 & 6.22 & 25.14 \\
\hline NR-TESPT & 23.24 & 16.33 & 6.91 & 29.73 \\
\hline ENR-TESPT & 24.43 & 16.22 & 8.21 & 33.61 \\
\hline $\mathrm{CCB}$ & 28.42 & 28.23 & 0.19 & 0.66 \\
\hline CNT & 31.20 & 31.18 & 0.02 & 0.06 \\
\hline Sample & \multicolumn{4}{|c|}{$\begin{array}{c}\gamma_{\mathrm{sl}} \\
{[\mathrm{mN} / \mathrm{m}]}\end{array}$} \\
\hline NR-CCB & \multicolumn{4}{|c|}{4.05} \\
\hline NR-CNT & \multicolumn{4}{|c|}{ m5.79 } \\
\hline ENR-CCB & \multicolumn{4}{|c|}{5.26} \\
\hline ENR-CNT & \multicolumn{4}{|c|}{7.17} \\
\hline NR/TESPT-CCB & \multicolumn{4}{|c|}{6.44} \\
\hline NR/TESPT-CNT & \multicolumn{4}{|c|}{8.56} \\
\hline ENR/TESPT-CCB & \multicolumn{4}{|c|}{7.57} \\
\hline ENR/TESPT-CNT & \multicolumn{4}{|c|}{9.84} \\
\hline
\end{tabular}
bers and their composites.

${ }^{*} S P_{\mathrm{s}}$ is surface polarity of sample obtained as the ratio $100 \cdot \gamma^{\mathrm{p}} / \gamma$. 

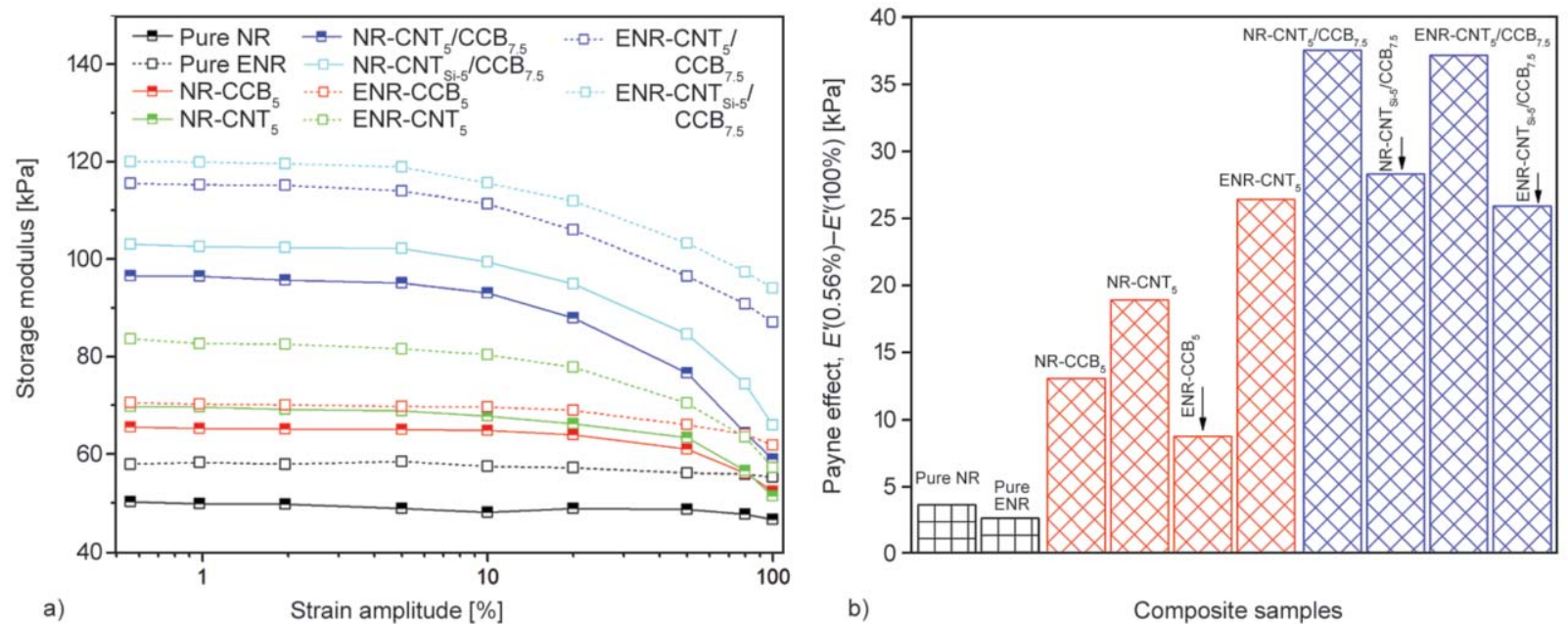

Figure 4. Relationship between storage modulus and strain amplitude (a) and Payne effects (b) of pure NR and ENR together with their vulcanizates with CCB, CNT and CNT/CCB hybrid filler with and without TESPT.

filler dispersion which increases the reinforcement efficiency in the ENR matrix according to higher interaction between filler and rubber molecules compared to the NR cases. Also, in Figure 4b, it is clearly seen that the Payne effect of solely CNT filled NR and ENR vulcanizates was higher than with only CCB filler. It is known that the Payne effect is due to CCB agglomeration in CCB filled NR and ENR vulcanizates. However, the Payne effect with CNT filler might be affected by the formed filler networks [21]. It is clear that the NR-CCB showed stronger $\mathrm{CCB}$ agglomerates and hence stronger Payne effect than the ENR-CCB composite. Similarly, ENR-CNT had stronger Payne effect than the unmodified NRCNT composite. This may be due to the chemical interactions of ENR and CNT surfaces, which improved CNT dispersion by preventing CNT re-agglomeration after compounding. Therefore, the chemical interactions might explain the reduced Payne effect in NR-CNT/CCB and ENR-CNT/CCB composites with TESPT (i.e., NR-CNT $\mathrm{Si}_{\mathrm{Si}-5} / \mathrm{CCB}_{7.5}$ and ENR-CNT $\mathrm{Ci}_{\mathrm{i}-5} / \mathrm{CCB}_{7.5}$ ) from those without the silane coupling agent, TESPT. The silanization reaction of TESPT and CNT/CCB linked the CNT/CCB networks to NR and ENR matrices and prevented the re-agglomeration of fillers. Thus, the dispersion of the fillers was significantly improved, which decreased the filler-filler interactions or the Payne effect. Also, the TESPT might act as the dispersing agent to improve effectively the filler dispersion in the rubber matrix. In Figure 4, it is also clear that the smallest Payne effect was achieved by the ENR-CNT/CCB composite with TESPT, where filler re-agglomeration is controlled by interactions of oxirane rings in ENR and functional groups on CNT and CCB surfaces, together with the silanization reaction of TESPT and CNT/CCB hybrid fillers. Therefore, the dispersion of CNT and CCB hybrid filler was significantly improved in the ENR matrix and in ENR with TESPT, achieving higher interfacial energy based on wetting ability (Table 3 ) and lower Payne effect; with more strongly decreasing trend of the storage modulus with strain amplitude than in the composites based on the unmodified NR (Figure 4).

\subsection{Temperature scanning stress relaxation (TSSR)}

TSSR technique has been recently used to elucidate the state of filler dispersion in rubbers and polymers as matrices [22]. The stress-temperature curve or relaxation modulus curve typically reveals the dependence of relaxation modulus on temperature in the temperature range $23-30^{\circ} \mathrm{C}$, which might be attributed to entropy effects. Other parts of the stress-temperature curve indicate the physically bound rubber $\left(30-90^{\circ} \mathrm{C}\right)$, sulfur crosslinks $\left(90-160^{\circ} \mathrm{C}\right)$, and rubber or polymer chain degradation $\left(160-220^{\circ} \mathrm{C}\right)$ [23]. Figure 5 shows the relaxation modulus-temperature curves of pure NR and ENR, and their vulcanizates with CCB, CNT and CNT/CCB hybrid filler with and without TESPT. It can be seen that the initial modulus of each vulcanizate indicates more reinforcement of the CNT filled NR and ENR composites than of the CCB filled NR and ENR composites. This might be due to CNT having higher interfacial energy than CCB (Table 3). In Figure 5, it is also seen that the initial modulus significantly increased from 

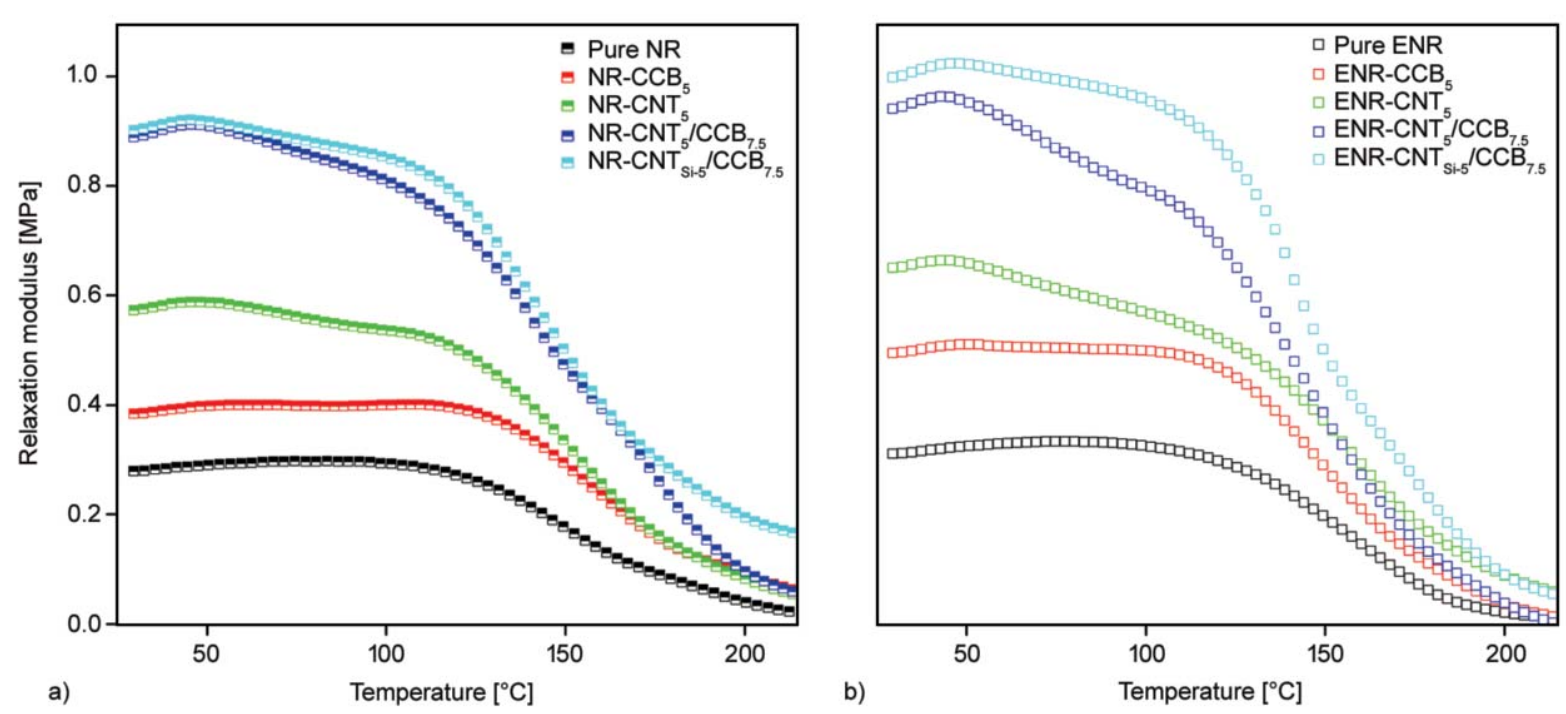

Figure 5. Relaxation modulus as a function of temperature for pure NR (a) and ENR (b) together with their vulcanizates with CCB, CNT and CNT/CCB hybrid filler with and without TESPT.

use of CNT/CCB hybrid filler and further increased with addition of TESPT. This might be due to the good dispersion and the interactions of $\mathrm{CNT} / \mathrm{CCB}$, NR or ENR, and TESPT. In Figure 5, it is also seen that the vulcanizates with ENR exhibited higher modulus than the in the one with NR matrix. This can be explained by stronger chemical interactions of ENR and filler surfaces than what the NR had, due to mechanisms proposed in Figure 2.

Figure 6 shows relaxation spectra as functions of temperature in the range from 30 to $90^{\circ} \mathrm{C}$, for pure NR and ENR together with their vulcanizates with $\mathrm{CCB}, \mathrm{CNT}$ and $\mathrm{CNT} / \mathrm{CCB}$ hybrid filler, without and with TESPT. It is noted that state of filler dispersion in NR and ENR matrices could be possibly elucidated by the peak heights (or areas under the peaks) in the relaxation spectra, in the temperature range 30 $90^{\circ} \mathrm{C}$. These peaks reflect the physically desorbed bound rubber in the rubber vulcanizates. Table 4(a) shows the peak areas in the temperature range 30$90^{\circ} \mathrm{C}$. It is seen that the NR and ENR vulcanizates with CNT showed larger peak areas than the ones with CCB. This indicates higher reinforcement capability for CNT than for CCB, due to the high specific surface of CNT. It is also seen that the peak area (physically bound rubber) increased with addition of the CNT-CCB hybrid filler in the NR and ENR matrices. This correlates to the total and physically bound rubbers that observed by swelling tests, as reported in Tables 4(b) and (c). In addition, the peak areas (in

Table 4. Peak areas in relaxation spectra over the temperature range $30-90^{\circ} \mathrm{C}$ (Figure 6), and totally, chemically and physically bound rubber contents calculated by swelling method for pure NR and ENR together with their vulcanizates with CCB, CNT and CNT/CCB hybrid fillers with and without TESPT.

\begin{tabular}{|c|c|c|c|c|}
\hline \multirow[t]{2}{*}{ Sample } & \multirow{2}{*}{$\begin{array}{c}\text { TSSR measurements } \\
\text { (a) } \\
\text { Peak area } \\
{\left[\mathrm{MPa}\left({ }^{\circ} \mathrm{C}\right)\right]}\end{array}$} & \multicolumn{3}{|c|}{ Bound rubber estimate } \\
\hline & & $\begin{array}{c}\text { (b) } \\
\text { Total bound rubber } \\
\text { content } \\
{[\%]}\end{array}$ & $\begin{array}{c}\text { (c) } \\
\text { Physically bound } \\
\text { rubber content } \\
{[\%]}\end{array}$ & $\begin{array}{c}\text { (d) } \\
\text { Chemically bound } \\
\text { rubber content } \\
{[\%]}\end{array}$ \\
\hline Pure NR & 0.42 & 1.15 & 1.15 & 0.00 \\
\hline NR-CCB 5 & 14.04 & 14.34 & 13.10 & 1.24 \\
\hline $\mathrm{NR}^{-\mathrm{CNT}_{5}}$ & 30.19 & 20.15 & 17.70 & 2.45 \\
\hline $\mathrm{NR}-\mathrm{CNT}_{5} / \mathrm{CCB}_{7.5}$ & 55.60 & 28.88 & 24.36 & 4.52 \\
\hline 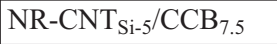 & 31.35 & 34.53 & 10.42 & 24.11 \\
\hline Pure ENR & 2.65 & 3.51 & 0.39 & 3.12 \\
\hline $\mathrm{ENR}_{-\mathrm{CCB}}$ & 26.79 & 26.45 & 14.00 & 12.45 \\
\hline $\mathrm{ENR}-\mathrm{CNT}_{5}$ & 34.02 & 37.23 & 19.34 & 17.89 \\
\hline $\mathrm{ENR}^{-\mathrm{CNT}_{5}} / \mathrm{CCB}_{7.5}$ & 68.64 & 39.12 & 16.78 & 22.34 \\
\hline $\mathrm{ENR} \mathrm{CNT}_{\mathrm{Si}-5} / \mathrm{CCB}_{7.5}$ & 59.93 & 44.45 & 14.29 & 30.16 \\
\hline
\end{tabular}




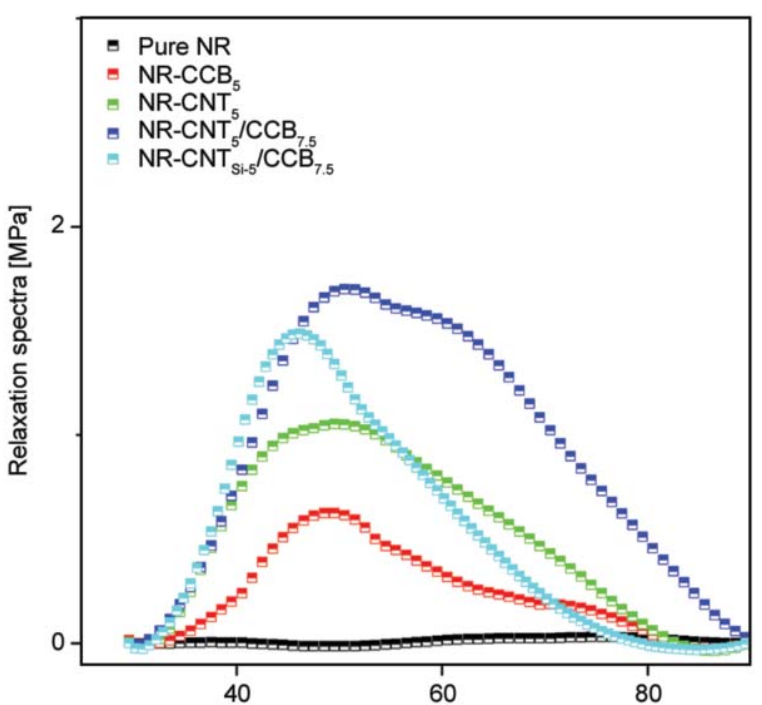

a)

Temperature $\left[{ }^{\circ} \mathrm{C}\right]$

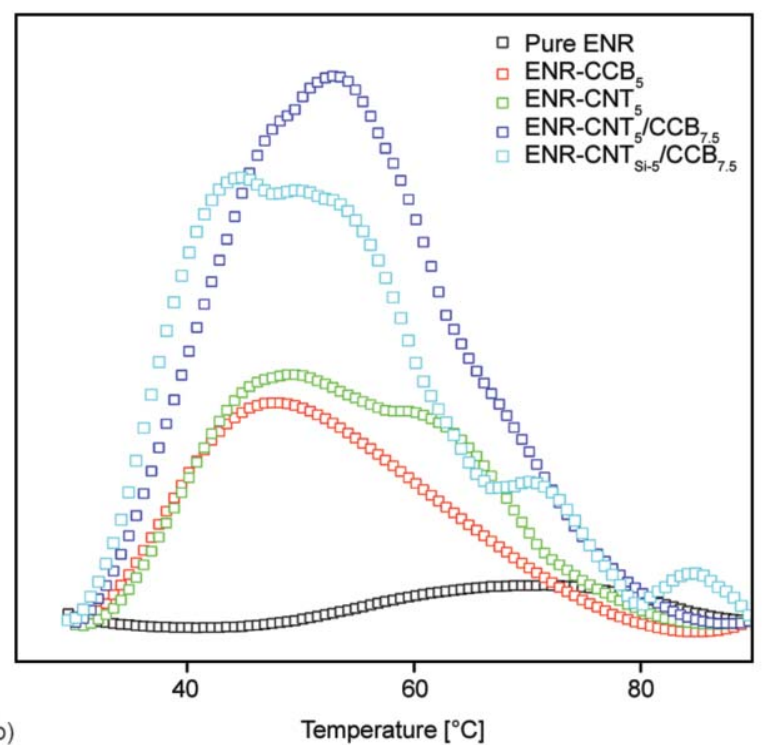

Figure 6. Relaxation spectra as functions of temperature in the range from 30 to $90^{\circ} \mathrm{C}$, for pure NR (a) and ENR (b) together with their vulcanizates with $\mathrm{CCB}, \mathrm{CNT}$ and $\mathrm{CNT} / \mathrm{CCB}$ hybrid filler with and without TESPT.

the range from 30 to $90^{\circ} \mathrm{C}$ ) together with total and physically bound rubbers also increased after addition of the CNT/CCB hybrid filler. This might be due to the increased volume fraction of fillers in the rubber matrix, with more interfacial area for rubber absorption. Interestingly, the relaxation spectrum and the peak areas in the temperature range $30-90^{\circ} \mathrm{C}$ for NR and ENR vulcanizates with CNT/CCB hybrid fillers decreased with addition of TESPT. This might be attributed to increased chemically bound rubber linking filler surfaces to rubber. Thus, the physical desorption of rubber with increasing temperature decreased [24]. This agrees with the increases with TESPT in total and chemically bound rubbers for both NR-CNT/CCB and ENR-CNT/CCB (Tables 4(b) and 4(d), respectively), while physically bound rubber significantly decreased. On comparing the NR and ENR vulcanizates, it is seen that high filler-rubber interactions were found for ENR and CNT, improving the CNT dispersion over that with unmodified NR. This is affirmed by the high peak areas at $30-90{ }^{\circ} \mathrm{C}$ for ENR vulcanizates with CNT, CNT/ $\mathrm{CCB}$ and $\mathrm{CNT} / \mathrm{CCB}$ with TESPT, relative to the respective NR vulcanizates.

The absorption mechanisms in terms of physically and chemically bound rubbers in NR and ENR vulcanizates with CNT/CCB hybrid fillers with and without TESPT are proposed in Figure 7. It is seen that, in the vulcanizates without TESPT, the total, physically and chemically bound rubbers in ENR are higher due to strong filler-rubber interactions of ENR with the functional groups on CNT and CCB surfaces. In addition, the physically bound rubber was also higher for ENR than for NR vulcanizates, due to the improved filler dispersion related to better filler-rubber interactions in ENR. Thus, the ENR vulcanizates with CNT/CCB hybrid filler showed larger relaxation spectrum peak areas than the NR vulcanizates (Figure 6). After addition of the TESPT, it is clearly seen that the total and chemically bound rubbers increased both in NR and ENR vulcanizates and therefore the physical desorption significantly decreased, as seen in Figure 6 and Table 4.

\subsection{Electrical and morphological properties}

Figure 8 shows electrical conductivity as a function of filler loading for NR and ENR vulcanizates with $\mathrm{CCB}, \mathrm{CNT}$ and CNT/CCB hybrid filler without and with TESPT. It is noted that one of the most sensitive tools to elucidate the formation of filler networks inside the rubber matrix is the electrical conductivity. In this work, the filler content that changes the material from an insulator to a conductor, so-called percolation threshold concentration $\left(\varphi_{c}\right)$ [25], was investigated. In Figure 8, it is seen that no percolation period was found for the vulcanizates with CCB: the CCB loadings were not high enough to reach the critical concentration and form a continuous connected network in the rubber matrix. On the other hand, the vulcanizates with CNT and CNT/CCB hybrid filler, with and without TESPT, clearly revealed percolation threshold concentrations that were estimated 
from the curve fits in Figure 8. The fundamental percolation theory provides Equations (8) and (9) that were fitted to the data [26]:

$\sigma_{\mathrm{DC}}=k\left(\varphi-\varphi_{\mathrm{c}}\right)^{\mathrm{t}}, \varphi>\varphi_{\mathrm{c}}$

$\log \sigma_{\mathrm{DC}}=\log k+t \cdot \log \left(\varphi-\varphi_{\mathrm{c}}\right)$

where $k$ is a constant and $t$ is a critical exponent or a dimensionality parameter of the filler network. $\varphi$ is the actual filler concentration.

$t$ can vary even within a single type of composite. This exponent is dependent on the dimensionality of

Table 5. The percolation threshold concentrations $\left(\varphi_{c}\right)$ and the $t$ values of the NR and ENR composites with CNT and CNT/CCB hybrid filler.

\begin{tabular}{|l|c|c|}
\hline \multicolumn{1}{|c|}{ Sample } & $\begin{array}{c}\boldsymbol{\varphi}_{\mathbf{c}} \\
{[\mathbf{p h r}]}\end{array}$ & $\boldsymbol{t}$ values \\
\hline NR-CNT & 3.0 & 1.4 \\
\hline NR-CNT/CCB & 2.0 & 1.7 \\
\hline NR-CNT $_{\mathrm{Si}} / \mathrm{CCB}$ & 1.0 & 1.8 \\
\hline ENR-CNT & 1.5 & 1.6 \\
\hline ENR-CNT/CCB & 0.5 & 1.8 \\
\hline ENR-CNT $_{\mathrm{Si}} / \mathrm{CCB}$ & 0.3 & 2.0 \\
\hline
\end{tabular}

the filler network. Theory of percolation predicts $t$ values in the range 1.6-2.0 for three-dimensional (3D) networks, and lower $t$ values indicate two-dimensional conductive networks [27].

Table 5 shows the percolation threshold concentrations $\left(\varphi_{c}\right)$ of NR-CNT, NR-CNT/CCB and NR$\mathrm{CNT}_{\mathrm{Si}} / \mathrm{CCB}$ vulcanizates are 3,2 and $1 \mathrm{phr}$ of $\mathrm{CNT}$, while lower $\varphi_{c}$ values were found in the ENR-CNT, ENR-CNT/CCB and ENR-CNT $\mathrm{Si}_{\mathrm{S}} / \mathrm{CCB}$ vulcanizates at $1.5,0.5$ and $0.3 \mathrm{phr}$ of CNT, respectively. On the other hand, the $t$ values of NR-CNT, NR-CNT/CCB and NR-CNT $\mathrm{Si}_{\mathrm{i}} / \mathrm{CCB}$ composites are 1.4, 1.7 and 1.8, whereas the $t$ values of ENR-CNT, ENR-CNT/CCB and ENR-CNT $\mathrm{Si}_{\mathrm{i}} / \mathrm{CCB}$ composites are 1.6, 1.8 and 2.0 , respectively. Therefore, the ENR vulcanizates achieved lower percolation thresholds than the NR vulcanizates with all the fillers tested. Also, the $t$ values (i.e., 1.6, 1.8 and 2.0) indicate three-dimensional filler networks in the ENR vulcanizates. This may be due to the stronger filler-rubber interactions of oxirane rings in ENR and polar functional groups on CCB and CNT surfaces, which restricted the re-agglomeration of fillers after compounding. Therefore, better dispersion of filler was obtained in the ENR

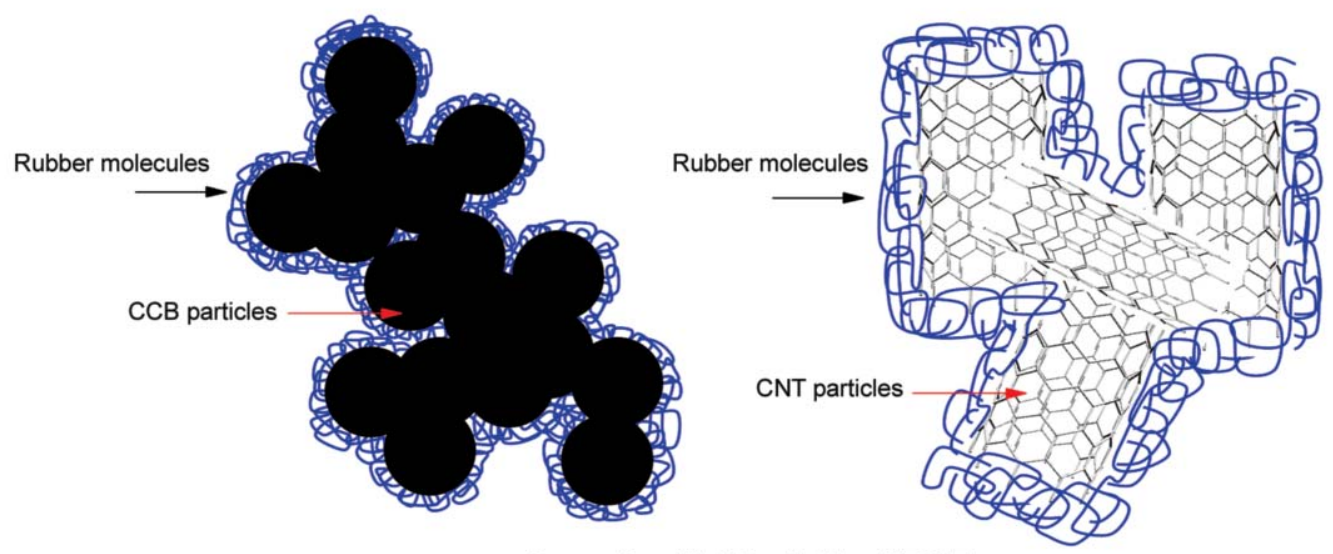

Composites with NR and without TESPT

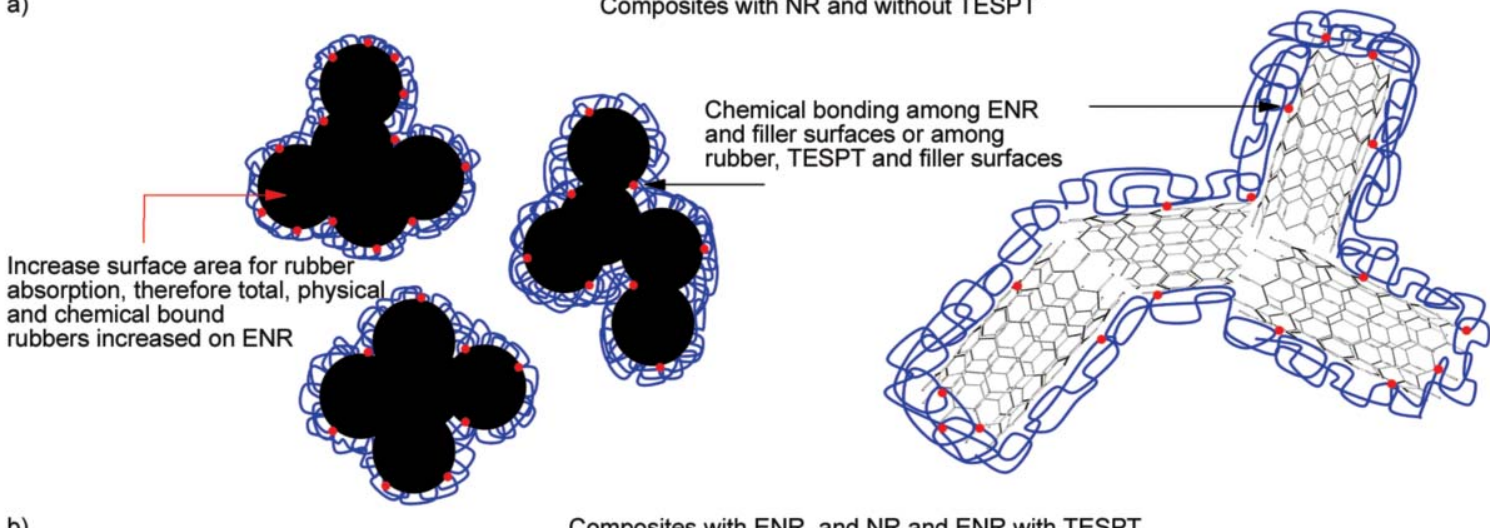

b)

Composites with ENR, and NR and ENR with TESPT

Figure 7. Proposed models of physically and chemically bound rubbers in NR and ENR composites with CCB, CNT and CNT/CCB hybrid filler without (a) and with (b) TESPT. 


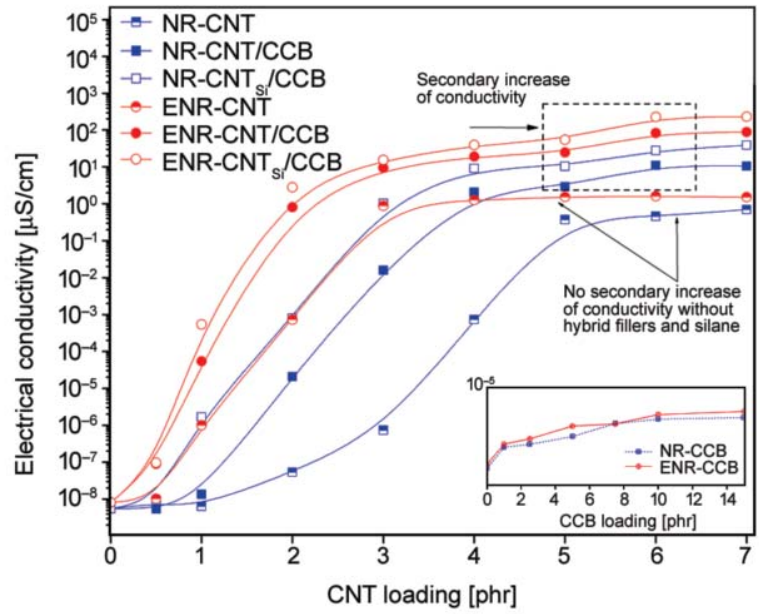

Figure 8. Electrical conductivity as a function of filler loading for NR and ENR vulcanizates with $\mathrm{CCB}, \mathrm{CNT}$ and $\mathrm{CNT} / \mathrm{CCB}$ hybrid filler with and without TESPT.

matrix. This is the rationale for ENR giving lower percolation threshold concentrations $\left(\varphi_{c}\right)$ in vulcanizates than the NR. Additionally, improved filler-rubber interactions not only enhance the conductivity of the rubber vulcanizates via improved filler dispersion, but also the reduce thickness of the rubber layer absorbed on filler surfaces. Table 6 indicates the bound rubber layer thickness $(\delta)$ calculated from Equation (5). It is clearly seen that the $\delta$ for ENR vulcanizates is less than for the NR vulcanizates, promoting lower $\varphi_{c}$ for the ENR composites. Furthermore, addition of CNT/CCB hybrid filler strongly reduced $\delta$ to approximately $3 \mathrm{~nm}$ (in the NR$\mathrm{CNT} / \mathrm{CCB}$ vulcanizate) and $2 \mathrm{~nm}$ (in the ENR-CNT/ $\mathrm{CCB}$ vulcanizate). This facilitated electron tunneling at the CNT-CCB-CNT linkages and therefore the percolation threshold of the vulcanizates was greatly reduced. Furthermore, in Figure 8, the optimal conductivity of the vulcanizates with $\mathrm{CNT} / \mathrm{CCB}$ hybrid filler was higher than with solely CCB or CNT. This

Table 6. The rubber layer thickness $(\delta)$ estimated from Equation (5).

\begin{tabular}{|c|c|}
\hline Sample & $\begin{array}{c}\delta \\
{[\mathrm{nm}]}\end{array}$ \\
\hline Pure NR and ENR & - \\
\hline NR-CCB 5 & 10.18 \\
\hline $\mathrm{NR}_{-\mathrm{CNT}}{ }_{5}$ & 8.22 \\
\hline $\mathrm{NR}^{-\mathrm{CNT}_{5}} / \mathrm{CCB}_{7.5}$ & 3.22 \\
\hline NR-CNT $_{\text {Si-5 }} / \mathrm{CCB}_{7.5}$ & 1.89 \\
\hline ENR-CCB ${ }_{5}$ & 8.86 \\
\hline $\mathrm{ENR}^{-\mathrm{CNT}_{5}}$ & 5.12 \\
\hline $\mathrm{ENR} \mathrm{CNT}_{5} / \mathrm{CCB}_{7.5}$ & 2.65 \\
\hline ENR-CNT $_{\mathrm{Si}-5} / \mathrm{CCB}_{7.5}$ & 1.51 \\
\hline
\end{tabular}

correlates well to the previous work [28] which showed significantly the improvement of the conductivity of the NR composites with CCB/CNT hybrid filler. In addition, in Figure 8, it was found that the conductivity and percolation concentration were again improved by addition of TESPT silane coupling agent. That is, the optimal conductivity increased to approximately $10^{3} \mu \mathrm{S} / \mathrm{cm}$ and the percolation threshold slightly decreased to the lowest value at $1 \mathrm{phr}$ of $\mathrm{CNT}$ in the $\mathrm{NR}-\mathrm{CNT}_{\mathrm{Si}} / \mathrm{CCB}$ and 0.3 phr of CNT in the ENR-CNT $\mathrm{Si}_{\mathrm{i}} / \mathrm{CCB}$ composites. This might be due to the chemical interactions with TESPT improving the CNT/CCB dispersion and lowering the $\delta$ to approximately $1 \mathrm{~nm}$. This small thickness of insulation supported electron tunneling between conductive filler particles and gave superior electrical properties.

Figure 9 shows SEM and TEM micrographs of NR and ENR vulcanizates with CNT/CCB hybrid filler, with and without TESPT. The morphological properties observed by SEM and TEM could be associated with the electric conductivities. In Figure 9, it is clearly seen that the CNT and CCB particles are randomly dispersed in both NR and ENR matrices. Also, some filler agglomerates are seen in both NR$\mathrm{CNT} / \mathrm{CCB}$ and ENR-CNT/CCB composites (Figures $9 \mathrm{a}$ to $9 \mathrm{~d}$ ). The agglomerates might hinder formation of connected paths with CNT-CCB-CNT linkages. Also, the rubber barrier around filler surfaces in the NR-CNT/CCB and ENR-CNT/CCB vulcanizates may still be electrically insulating. Moreover, the agglomeration of fillers particles inside rubber matrix causes electron scattering that decreases conductivity [4]. In Figure 9, it is also seen that homogenous dispersion of fillers particles was achieved with addition of TESPT in both NR and ENR vulcanizates, with $\mathrm{CNT} / \mathrm{CCB}$ hybrid filler. Therefore, the dispersion of CNT and CCB was improved and the $\mathrm{CCB}$ aggregates possibly bridged the nanotubes (Figures 9e and 9h). This reduced the gaps between filler particles in the rubber matrix, as reflected by the very low $\delta$ of approximately $1 \mathrm{~nm}$ in Table 6 . Thus, the electric charges easily moves and tunneled along the fillers, and this is why the least percolation threshold and the highest electrical conductivity were achieved by the $\mathrm{ENR}-\mathrm{CNT}_{\mathrm{Si}} / \mathrm{CCB}$ composite. Influence of TESPT on improvement of electrical conductivity of the NR and ENR vulcanizates with $\mathrm{CNT} / \mathrm{CCB}$ hybrid filler with the concentrations of 1 (before $\varphi_{c}$ ), 3 (during $\varphi_{c}$ ) and $5 \mathrm{phr}$ 

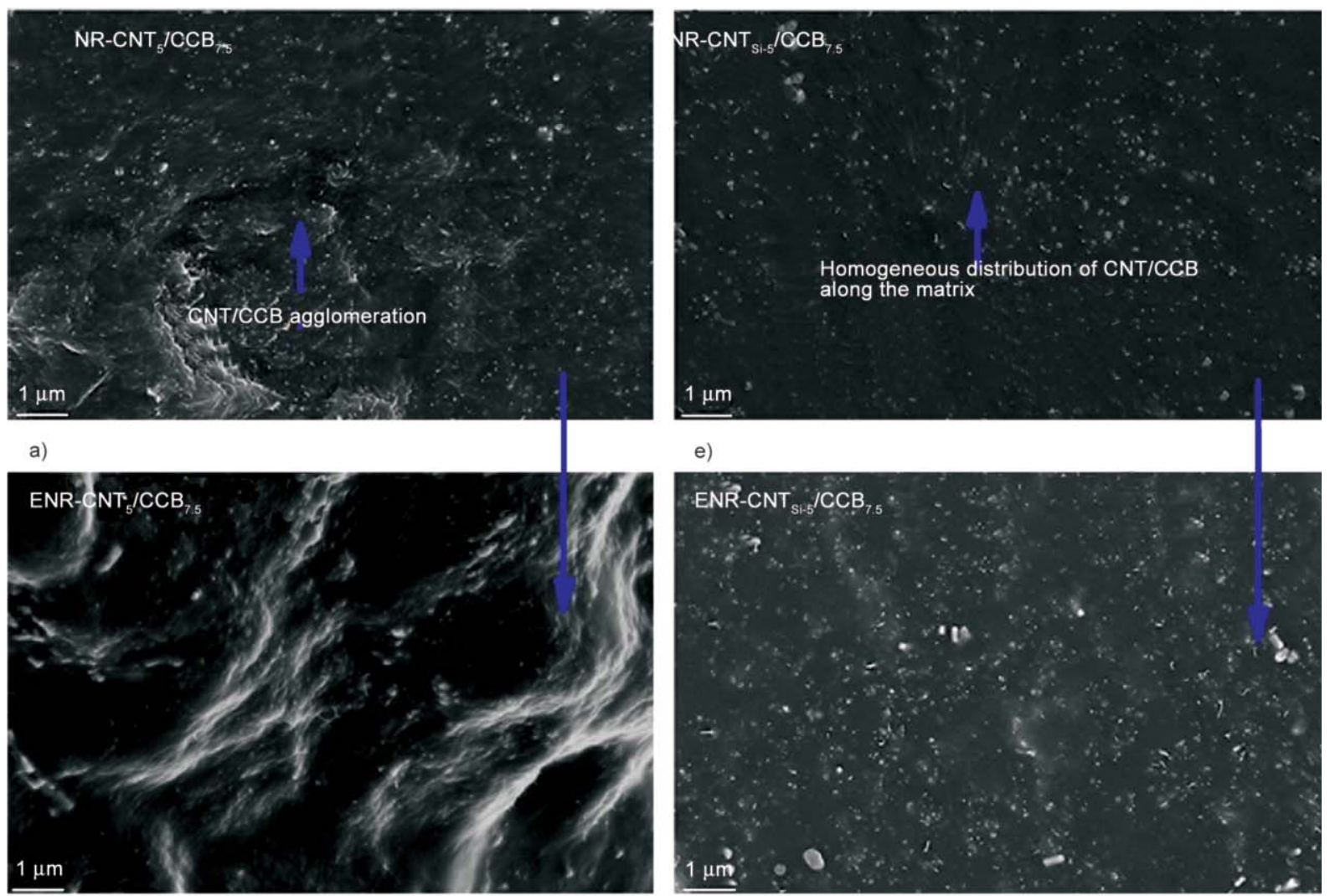

b)

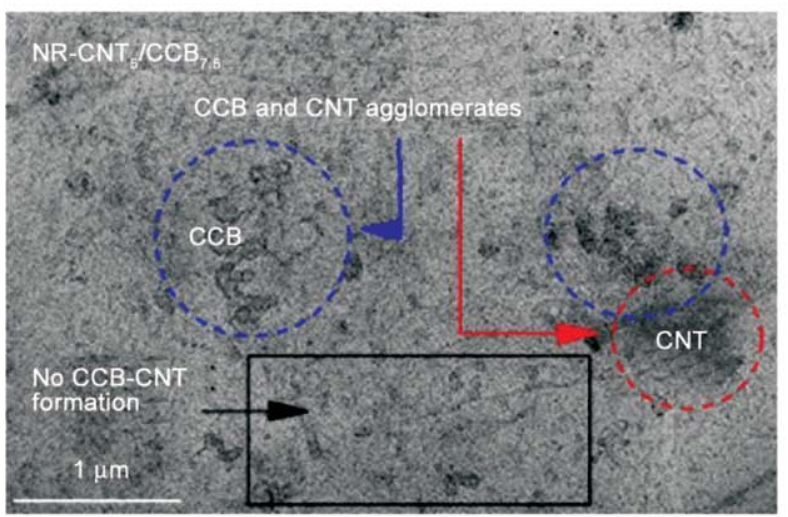

f)

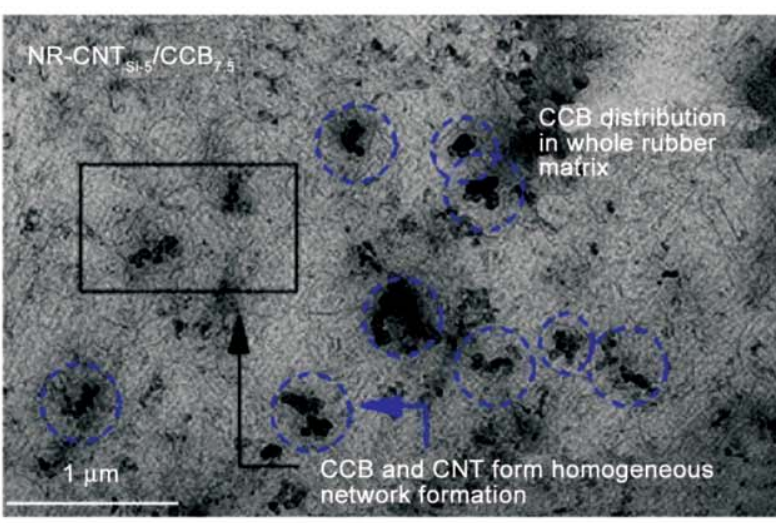

c)

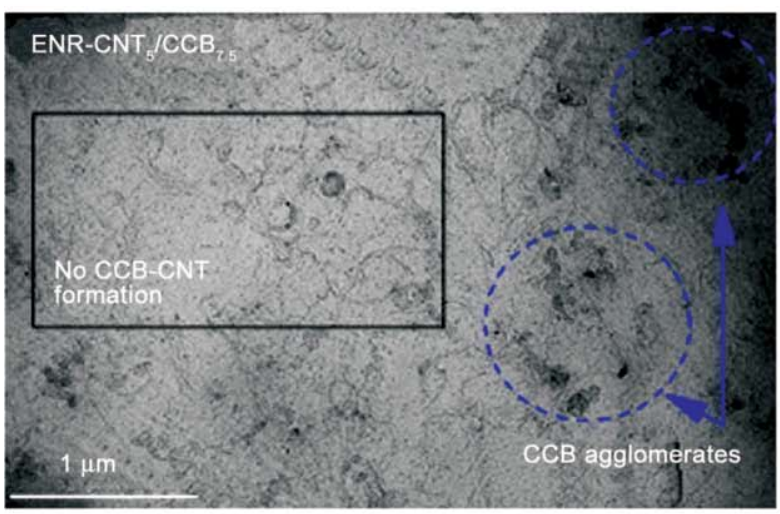

g)

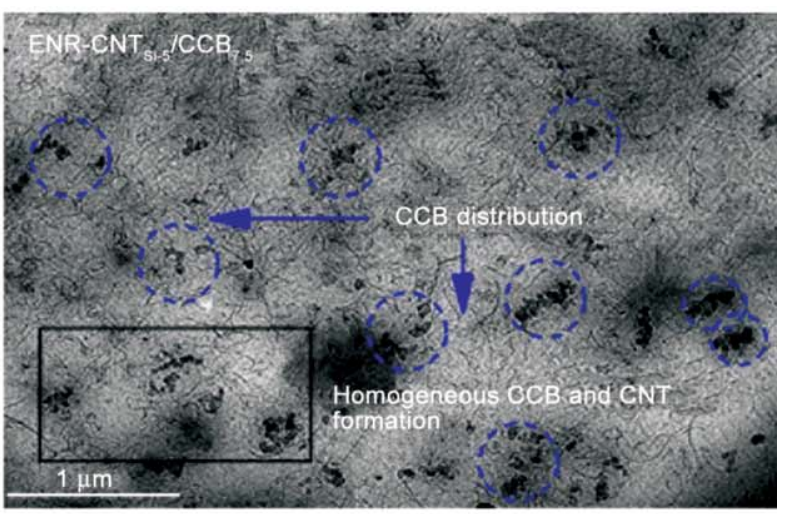

d)

h)

Figure 9. SEM micrographs of NR-CNT $/ \mathrm{CCB}_{7.5}$ (a), ENR-CNT $5 / \mathrm{CCB}_{7.5}$ (b), $\mathrm{NR}_{-\mathrm{CNT}} \mathrm{Si}_{\mathrm{Si}-5} / \mathrm{CCB}_{7.5}$ (e), and ENR-CNT $\mathrm{CNi}_{\mathrm{S}} / \mathrm{CCB}_{7.5}$ (f) and TEM micrographs of NR-CNT $/ \mathrm{CCB}_{7.5}$ (c), ENR-CNT $5 / \mathrm{CCB}_{7.5}$ (d), NR-CNT $\mathrm{Ci}_{\mathrm{Si} 5} / \mathrm{CCB}_{7.5}$ (g), and ENR$\mathrm{CNT}_{\mathrm{Si}-5} / \mathrm{CCB}_{7.5}(\mathrm{~h})$ for NR and ENR vulcanizates with CNT/CCB hybrid filler with and without TESPT. 

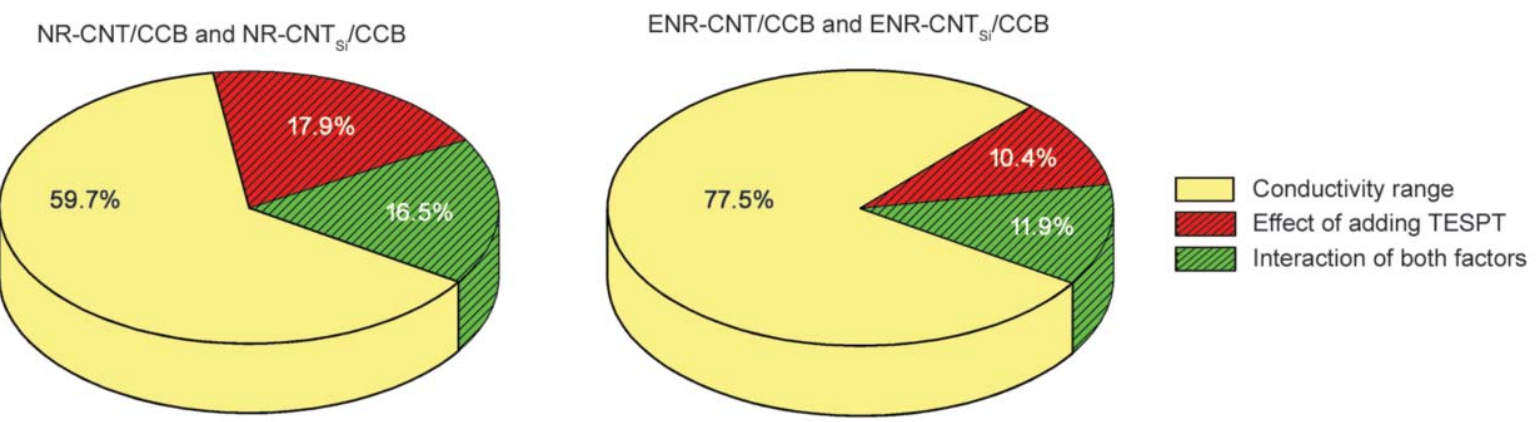

Figure 10. Contributions of TESPT addition to electrical conductivity of the NR and ENR vulcanizates with CNT/CCB hybrid filler at the concentrations of 1 (before $\varphi_{\mathrm{c}}$ ), 3 (during $\varphi_{\mathrm{c}}$ ) and $5 \mathrm{phr}$ (beyond $\varphi_{\mathrm{c}}$ ) of CNT, according to ANOVA.

(beyond $\varphi_{\mathrm{c}}$ ) of CNT was analyzed by 'Analysis of Variance' (ANOVA). The contributions of each factor were calculated based on Equation (10) [29] and plotted in Figure 10:

$S S_{\mathrm{T}}=\sum_{\mathrm{i}=1}^{\mathrm{n}}\left(y_{\mathrm{i}}-\bar{y}\right)^{2}$

where SST is the total sum of squared deviations which is the sum of squared differences between a dependent variable $\left(y_{\mathrm{i}}\right)$ and its mean $(\bar{y})$.

In Figure 10, it is seen that the contributions to conductivity from addition of TESPT in the CNT/CCB hybrid filler filled NR and ENR vulcanizates with and without TESPT are significant different. That is, NR contributed less to conductivity than the ENR in vulcanizates. However, in NR vulcanizate the addition of TESPT contributed more than in ENR as the conductivity of NR-CNT/CCB vulcanizates significantly increased with addition of TESPT. Therefore, it is concluded that the addition of TESPT silane coupling agent more strongly increased electrical conductivity in NR than in ENR vulcanizates.

\subsection{Dielectric constant}

Figure 11 shows the dielectric constant as a function of CNT loading in NR and ENR vulcanizates, with $\mathrm{CNT} / \mathrm{CCB}$ hybrid filler with and without TESPT. It is clearly seen that the dielectric constant (charge capacitor) increases similar to the electrical conductivity (charge inductor) with filler loading. It is recognized that the charge capacitance of rubber vulcanizates might have contribution from by the isolated CNT particles, as seen in the model proposed in Figure 12. It can be seen that the electric charges are scattered and cannot tunnel to the nearby filler particles (i.e., CNT or CCB) at the ends of the tubes. This increased the remaining electric charges inside the

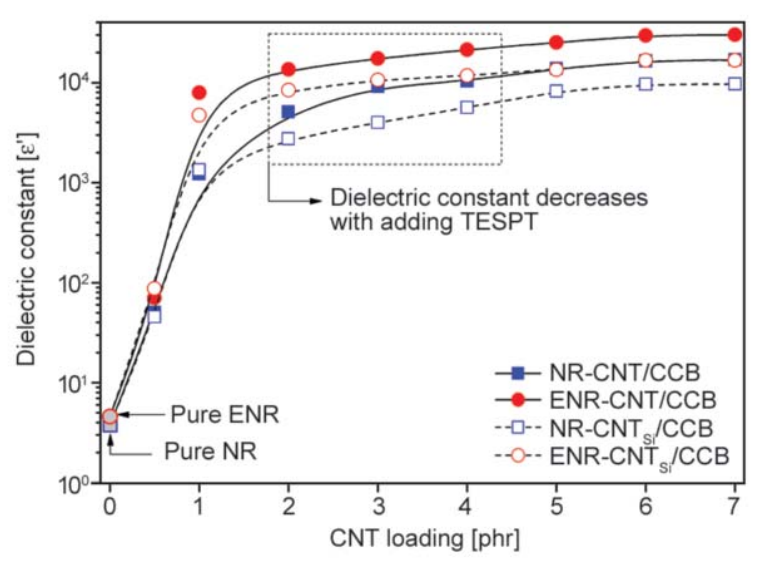

Figure 11. Dielectric constant as a function of CNT loading for NR and ENR vulcanizates with CNT/CCB hybrid filler with and without TESPT.

rubber vulcanizates. Therefore, the capacitance increased when the filler particles did not form conductive pathways. The dielectric constant increased with CNT loading in the CNT/CCB filled rubber vulcanizates. Interestingly, the dielectric constants of NR-CNT/CCB and ENR-CNT/CCB vulcanizates significantly decreased with addition of TESPT silane coupling agent. This might be due to reduction in isolated CNT particles and formation of a three-dimensional network. This correlates to $t=1.8$ in the NR-CNT ${ }_{\mathrm{Si}} / \mathrm{CCB}$ and $t=2.0$ in the ENR-CNT $\mathrm{Si}_{\mathrm{S}} / \mathrm{CCB}$ composites (Figure 8). Therefore, addition of TESPT to the CNT/CCB filled NR and ENR vulcanizates significantly improved the mechanical properties (Figures 5 and 6), the percolation threshold concentration, the optimal electrical conductivity (Figure 8) and the dielectric constant (Figure 11). In addition, it is noted here that superior electrical conductivity together with low dielectric constant were found with the addition of TESPT. This could enable smart materials for such applications as an actuator, where high conductivity and low dielectric properties are needed. 


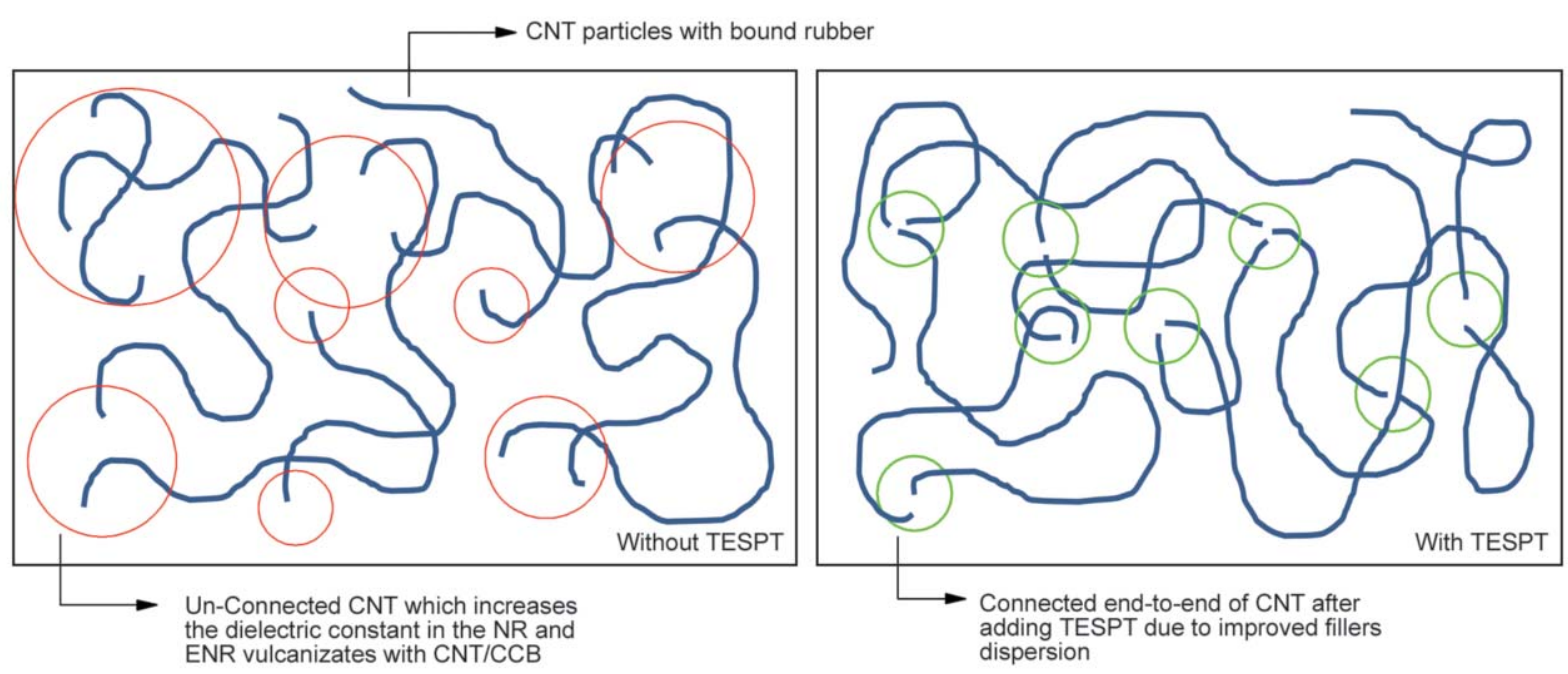

Figure 12. Proposed models of the CNT formation in the CNT/CCB filled NR and ENR vulcanizates with and without TESPT in order to clarify decreasing trend of the dielectric constant.

\subsection{Curing properties}

The filler networks carry not only charges along the conductive filler pathways, but they also facilitate the movement of phonons that contribute to thermal conductivity [30]. Figure 13 shows scorch time $\left(t_{\mathrm{s} 1}\right)$, cure time $\left(t_{90}\right)$ and torque difference $\left(M_{\mathrm{H}^{-}} M_{\mathrm{L}}\right)$ for the $\mathrm{NR}$ and ENR composites with CNT/CCB hybrid filler, without and with TESPT. It is seen that the $t_{\mathrm{s} 1}$ of the CNT/CCB composites was significantly reduced by addition of TESPT. This may be attributed to the improved filler distribution and formation of three-dimensional filler networks in the rubber matrix, carrying both electrons and phonons in the filled rubber. Hence, the rubber was activated by thermal conductivity to crosslink faster than without TESPT silane coupling agent. The thermal conductivity might affect the accelerator (MBTs), activator and sulfur curing agent to commence the vulcanization of rubber molecules. However, in Figure 13a, it is seen that the $t_{90}$ was not significantly changed by the addition of TESPT. This means that the compounds with silane coupling needed more time to crosslink despite earlier start of the curing process, when compared to the compound without TESPT. This is reflected in the higher torque difference $\left(M_{\mathrm{H}}-M_{\mathrm{L}}\right)$ between maximum and minimum torques in the curing curves (Figure 13b). It is also seen that $M_{\mathrm{H}}-M_{\mathrm{L}}$ significantly increased with addition of TESPT and with filler loading. This may be due to enhanced crosslink density from chemical bridging with silane molecules, forming new chemical linkages of rubbersilane-CNT and rubber-silane-CCB types. Also, the chemical crosslinking reactions between ENR and TESPT molecules might be the reason for higher crosslink density of ENR than the NR vulcanizates. This may be practically useful to manufacturing since the cure time was unaffected but higher degree of crosslinking was achieved, which enhances
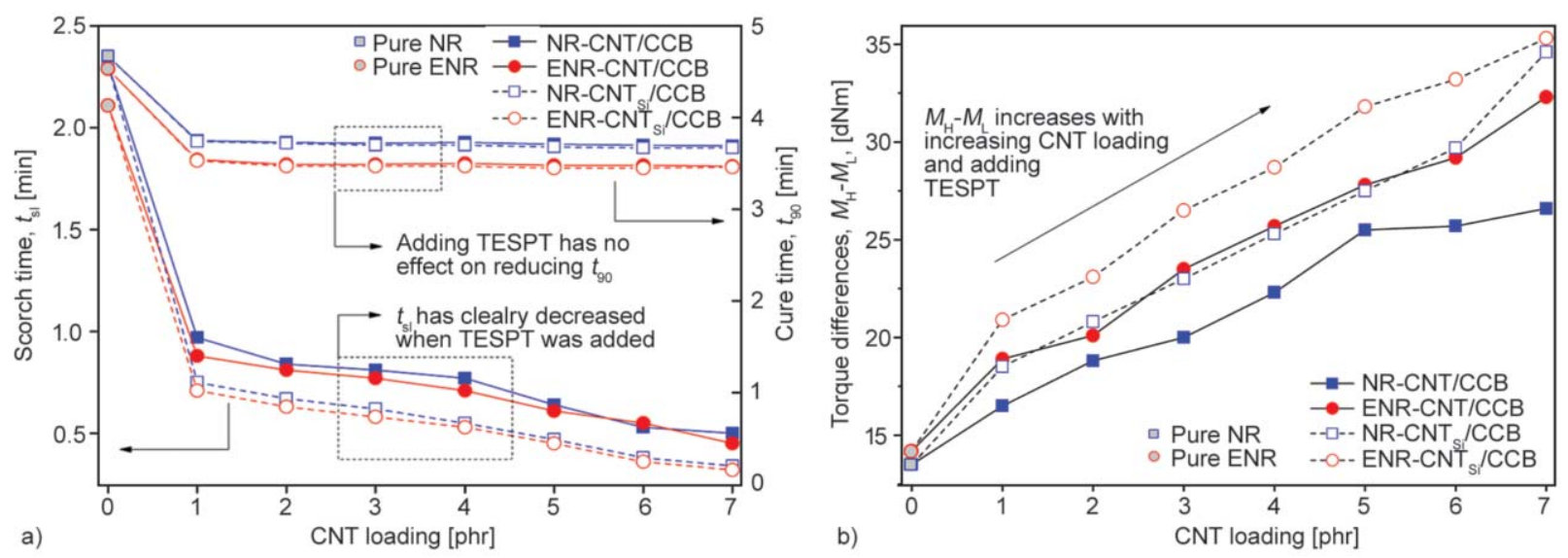

Figure 13. Scorch time $\left(t_{\mathrm{s} 1}\right)$ and cure time $\left(t_{90}\right)$ (a) together with the torque difference $\left(M_{\mathrm{H}}-M_{\mathrm{L}}\right)$ (b) as functions of CNT loading for NR and ENR composites with CNT/CCB hybrid filler with and without TESPT. 
mechanical (Figures 5 and 6), electrical (Figures 8 and 11) and thermal properties (Figure 13).

\section{Conclusions}

The CCB, CNT and CNT/CCB filled NR and ENR vulcanizates without and with TESPT silane coupling agent were carefully prepared with an internal mixer and a two-roll mill. The ATR-FTIR was then used to characterize the un-vulcanized and vulcanized rubber composites. The silanization of $\mathrm{CCB}$ and CNT surfaces with TESPT was confirmed along with coupling reactions with NR and ENR. This agrees with the relaxation spectra from TSSR measurement. In addition, wetting abilities of fillers and rubber correlated well with the Payne effects of the composites. That is, filler dispersion in the rubber matrix was improved by the addition of TESPT. This affected the morphological properties and formation of three-dimensional filler networks with conductive pathways that were clearly seen in the NR and ENR matrices. Furthermore, the optimal conductivity of the rubber vulcanizates was significantly increased, while the percolation threshold concentration was effectively reduced to the lowest value of approximately 0.3 phr of CNT in the ENR-CNT/CCB composite with TESPT. This might be due to strongly decreased thickness of the bound rubber layer on filler surfaces, to approximately $1 \mathrm{~nm}$. Therefore, electrons could tunnel between the filler particles and provide superior electrical conductivity. It was also found that the TESPT silane coupling agent in NR and ENR vulcanizates with CNT/CCB hybrid filler reduced the dielectric constant, along with providing superior conductivity. In addition curing properties of the composites were enhanced, with increased crosslinking density despite decreased scorch time. Therefore, adding TESPT to the NR and ENR vulcanizates with CNT and CCB hybrid filler gave superior conductive material with lower dielectric constant.

\section{Acknowledgements}

The authors gratefully acknowledge financial support in the form of a Postdoctoral Fellowship from the Prince of Songkla University. The Research and Development Office (RDO), Prince of Songkla University Hat Yai campus and the Faculty of Science and Industrial Technology, Prince of Songkla University Surat Thani campus, are acknowledged for access to facilities and equipment. In addition, we would like to thank Assoc. Prof. Dr. Seppo Karrila for proof-reading.

\section{References}

[1] Nakaramontri Y., Kummerlöwe C., Nakason C., Vennemann N.: The effect of surface functionalization of carbon nanotubes on properties of natural rubber/carbon nanotube composites. Polymer Composites, 36, 2113 2122 (2015).

http://doi.org/10.1002/pc.23122

[2] Nakaramontri Y., Nakason C., Kummerlöwe C., Vennemann N.: Effects of in situ functionalization of carbon nanotubes with bis(triethoxysilylpropyl) tetrasulfide (TESPT) and 3 aminopropyltriethoxysilane (APTES) on properties of epoxidized natural rubber-carbon nanotube composites. Polymer Engineering and Science, 55, 2500-2510 (2016).

http://doi.org/10.1002/pen.24140

[3] Ma P-C., Siddiqui N. A., Marom G., Kim J-K.: Dispersion and functionalization of carbon nanotubes for polymer-based nanocomposites: A review. Composites Part A: Applied Science and Manufacturing, 41, 1345-1367 (2010). http://doi.org/10.1016/j.compositesa.2010.07.003

[4] Nakaramontri Y., Pichaiyut S., Wisunthorn S., Nakason C.: Hybrid carbon nanotubes and conductive carbon black in natural rubber composites to enhance electrical conductivity by reducing gaps separating carbon nanotube encapsulates. European Polymer Journal, 90, 467484 (2017).

http://doi.org/10.1016/j.eurpolymj.2017.03.029

[5] Kaewsakul W., Sahakaro K., Dierkes W. K., Noordermeer J. W. M.: Optimization of mixing conditions for silica-reinforced natural rubber tire tread compounds. Rubber Chemistry and Technology, 2, 277-294 (2012). http://doi.org/10.5254/rct.12.88935

[6] Nakaramontri Y., Kummerlöwe C., Nakason C., Vennemann N.: Effect of modified natural rubber and functionalization of carbon nanotubes on properties of natural rubber composites. Advanced Materials Research, 844, 301-304 (2014). http://doi.org/10.4028/www.scientific.net/AMR.844.301

[7] Owens D. K., Wendt R. C.: Estimation of the surface free energy of polymers. Journal of Applied Polymer Sciences, 13, 1741-1747 (1969).

http://doi.org/10.1002/app.1969.070130815

[8] Stöckelhuber K. W., Das A., Jurk R., Heinrich G.: Contribution of physico-chemical properties of interfaces on dispersibility, adhesion and flocculation of filler particles in rubber. Polymer, 51, 1954-1963 (2010).

http://doi.org/10.1016/j.polymer.2010.03.013

[9] Vennemann N., Bökamp K., Bröker D.: Crosslink density of peroxide cured TPV. Macromolecular Symposia, 245-246, 641-650 (2006). http://doi.org/10.1002/masy.200651391

[10] Vennemann N., Heinz M.: Thermoelastic behaviour of filled elastomers model analysis and experimental investigation. Kautschuk Gummi Kunststoffe, 61, 447-454 (2008). 
[11] Guggilla P., Batra A. K., Edwards M. E.: Electrical characterization of $\mathrm{LiTaO}_{3}: \mathrm{P}(\mathrm{VDF}-\mathrm{TrFE})$ composites. Journal of Materials Science, 44, 5469-5474 (2007). http://doi.org/10.1007/s10853-009-3753-8

[12] Wolff S., Wang M-J., Tan E-H.: Filler-elastomer interactions. Part VII. Study on bound rubber. Rubber Chemistry and Technology, 66, 163-177 (1993). http://doi.org/10.5254/1.3538304

[13] Le H. H., Pham T., Henning S., Klehm J., Wießner S., Stöckelhuber K-W., Das A., Hoang X. T., Do Q. K., Wu M., Vennemann N., Heinrich G., Radusch H-J.: Formation and stability of carbon nanotube network in natural rubber: Effect of non-rubber components. Polymer, 73, 111-121 (2015).

http://doi.org/10.1016/j.polymer.2015.07.044

[14] Coates J.: Interpretation of infrared spectra, A practical approach. in 'Encyclopedia of analytical chemistry' (ed.: Meyers R. A.) Wiley, New York, 10815-10837 (2006). http://doi.org/10.1002/9780470027318.a5606

[15] Nakaramontri Y., Nakason C., Kummerlöwe C., Vennemann N.: Influence of modified natural rubber on properties of natural rubber-carbon nanotube composites. Rubber Chemistry and Technology, 88, 199-218 (2015). http://doi.org/10.5254/rct.14.85949

[16] Nakaramontri Y., Nakason C., Kummerlöwe C., Vennemann N.: Enhancement of electrical conductivity and filler dispersion of carbon nanotube filled natural rubber composites by latex mixing and in situ silanization. Rubber Chemistry and Technology, 89, 272-291 (2016). http://doi.org/10.5254/rct.15.84848

[17] Varga M., Izak T., Vretenar V., Kozak H., Holovsky J., Artemenko A., Hulman M., Skakalova V., Lee D. S., Kromka A.: Diamond/carbon nanotube composites: Raman, FTIR and XPS spectroscopic studies. Carbon, 111, 54-61 (2017). http://doi.org/10.1016/j.carbon.2016.09.064

[18] Choi S-S., Kim J-C., Ko J-E., Seok C. Y., Gi S. W.: Influence of coupling agent on properties of carbon blackreinforced SBR and NR/SBR vulcanizates. Journal of Industrial and Engineering Chemistry, 13, 1017-1022 (2007).

[19] Uthaipan N., Jarnthong M., Peng Z., Junhasavasdikul B., Nakason C., Thitithammawong A.: Micro-scale morphologies of EPDM/EOC/PP ternary blends: Relating experiments to predictive theories of dispersion in melt mixing. Material and Design, 100, 19-29 (2016). http://doi.org/10.1016/j.matdes.2016.03.099

[20] Adão M. H. V. C., Saramago B. J. V., Fernandes A. C.: Estimation of the surface properties of styrene-acrylonitrile random copolymers from contact angle measurements. Journal of Colloid and Interface Science, 217, 94-106 (1999).

http://doi.org/10.1006/jcis.1999.6279
[21] Bokobza L.: Enhanced electrical and mechanical properties of multiwall carbon nanotube rubber composites. Polymer Advanced and Technology, 23, 1543-1549 (2012). http://doi.org/10.1002/pat.3027

[22] Vennemann N., Heinz M., Wu M.: Experimental investigations and development of a model for the description of the thermoelastic properties of carbon black filled SBR-vulcanizates. Kautschuk Gummi Kunststoffe, 64, 40-46 (2011).

[23] Vennemann N., Schwarze C., Kummerlöwe C.: Determination of crosslink density and network structure of NR vulcanizates by means of TSSR. Advanced Materials Research, 844, 482-485 (2014). http://doi.org/10.4028/www.scientific.net/AMR.844.482

[24] Vennemann N., Wu M., Heinz M.: Thermoelastic properties and relaxation behavior of S-SBR/silica vulcanizates. Rubber World, 246, 18-23 (2012).

[25] Bokobza L.: Multiwall carbon nanotube elastomeric composites: A review. Polymer, 48, 4907-4920 (2007). http://doi.org/10.1016/j.polymer.2007.06.046

[26] Kirkpatrick S.: Percolation and conduction. Reviews of Modern Physics, 45, 574-588 (1973).

http://doi.org/10.1103/RevModPhys.45.574

[27] Shrivastava N. K., Khatua B. B.: Development of electrical conductivity with minimum possible percolation threshold in multi-wall carbon nanotube/polystyrene composites. Carbon, 49, 4571-4579 (2011).

http://doi.org/10.1016/j.carbon.2011.06.070

[28] Natarajan T. S., Eshwaran S. B., Stöckelhuber K. W., Wießner S., Pötschke P., Heinrich G., Das A.: Strong strain sensing performance of natural rubber nanocomposites. ACS Applied Materials and Interfaces, 9, 48604872 (2017).

http://doi.org/10.1021/acsami.6b13074

[29] Tang S. H., Tan Y. J., Sapuan S. M., Sulaiman S., Ismail N., Samin R.: The use of Taguchi method in the design of plastic injection mould for reducing warpage. Journal of Materials Processing Technology, 182, 418-426 (2007). http://doi.org/10.1016/j.jmatprotec.2006.08.025

[30] Varshney V., Patnaik S. S., Roy A. K., Barry L. F.: Modeling of thermal conductance at transverse CNT-CNT interfaces. Journal of Physical Chemistry Part C, 114, 16223-16228 (2010). http://doi.org/10.1021/jp104139x 